\title{
WestVirginiaUniversity
}

THE RESEARCH REPOSITORY @ WVU

Graduate Theses, Dissertations, and Problem Reports

2008

\section{Assessing the limitations of oak in OSB}

Brian D. Cox

West Virginia University

Follow this and additional works at: https://researchrepository.wvu.edu/etd

\section{Recommended Citation}

Cox, Brian D., "Assessing the limitations of oak in OSB" (2008). Graduate Theses, Dissertations, and Problem Reports. 2628.

https://researchrepository.wvu.edu/etd/2628

This Thesis is protected by copyright and/or related rights. It has been brought to you by the The Research Repository @ WVU with permission from the rights-holder(s). You are free to use this Thesis in any way that is permitted by the copyright and related rights legislation that applies to your use. For other uses you must obtain permission from the rights-holder(s) directly, unless additional rights are indicated by a Creative Commons license in the record and/ or on the work itself. This Thesis has been accepted for inclusion in WVU Graduate Theses, Dissertations, and Problem Reports collection by an authorized administrator of The Research Repository @ WVU. For more information, please contact researchrepository@mail.wvu.edu. 


\title{
Assessing the Limitations of Oak in OSB
}

\author{
Brian D. Cox
}

Thesis submitted to the Davis College of Agriculture, Forestry, and Consumer Sciences at West Virginia University

in partial fulfillment of the requirements for the degree of

\author{
Master of Science \\ in \\ Forest Resource Management \\ Dr. Joseph McNeel, chair \\ Dr. Gangarao Hota \\ Jody Gray, M.S. \\ Dr. John Noffsinger \\ Dr. Jinxin Wang
}

Division of Forestry

Wood Science

Morgantown, West Virginia

2008

Keywords: oriented strand board, oak utilization, compaction ratio 


\section{Abstract \\ Assessing the Limitations of Oak in OSB \\ By \\ Brian D. Cox}

Recent studies show that oak logging residue makes up a disproportionate amount of the total residue left behind after the harvest (Grushecky et al. 2006). The majority of logging residue tends to be low-grade wood. A primary outlet for low-grade wood in WV is oriented strand board (OSB) mills. Currently, a very small percentage of oak species is utilized in OSB, largely due to the inability to produce quality strands from oak and partially due to the uncertainty of quantity that may be used in panels.

This research investigated the stranding of oak species along with utilizing oak strands in the production of OSB. Different proportions of oak were used in panel production to assess the effect of oak on the strength properties of the OSB panels. Standard ASTM testing procedures were used to determine the actual properties and statistical relationships between these variables identified.

Results of this research revealed that quality strands can be produced from oak. Investigation results also indicated that a minimum of $25 \%$ oak may be used in the production of OSB panels without sacrificing panel strength properties. 


\section{Acknowledgements}

The author wishes to thank Weyerhaueser of Heaters, WV for the donation of materials and use of equipment that made this research possible. I would also like to thank Weyerhaeuser of Buckhannon, WV for the use of their laboratory equipment in testing research specimens. Special thanks go to Jody Gray for providing guidance and knowledge through every step of this research. I would also like to thank Dr. Joseph McNeel and Dr. Gangarao Hota for all of their time spent advising me on this research. In addition, I would also like to thank Shawn Grushecky for assistance with statistical analysis and sparking the interest in this research through inventorying logging residue. Last, but not least, I would like to give special thanks to Ben Weekly and Lucas Cunningham for all of their hard work assisting me anytime I needed help during this research. Thanks again to all that I have mentioned and to any that I may have left out. 


\section{Table of Contents}

ABSTRACT

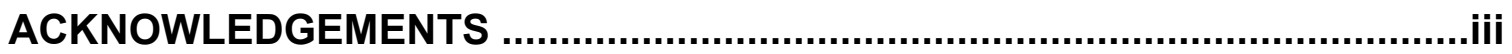

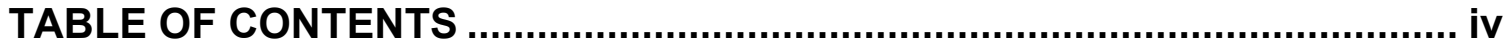

LIST OF FIGURES

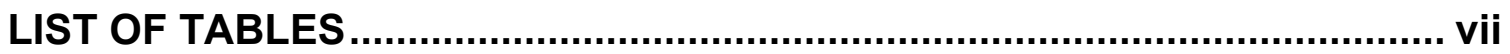

LIST OF SYMBOLS / NOMENCLATURE ..................................................... viii

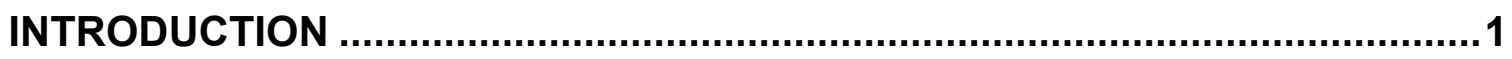

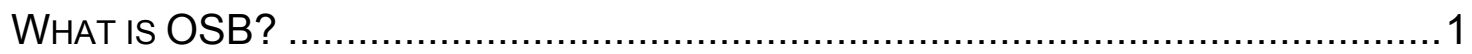

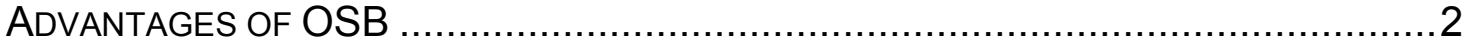

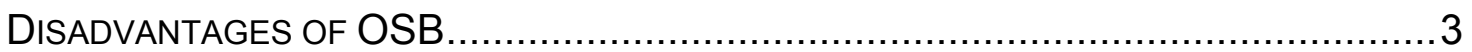

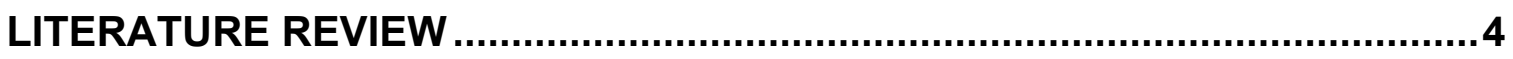

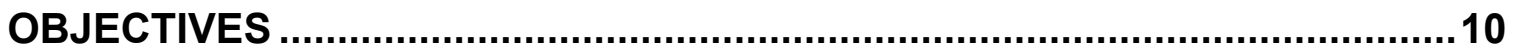

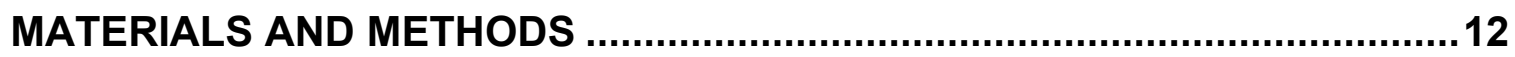

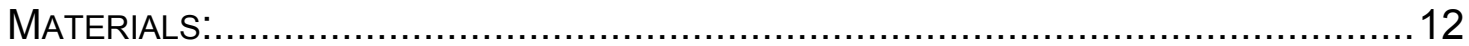

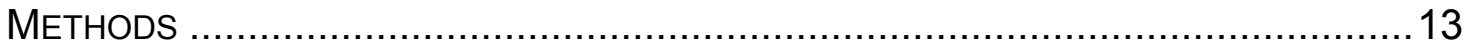

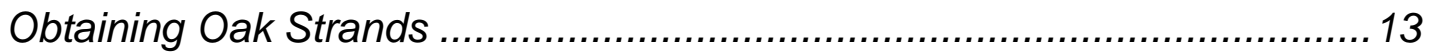

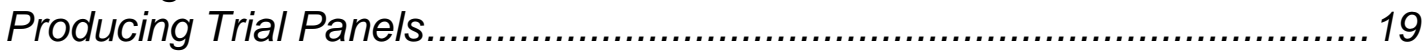

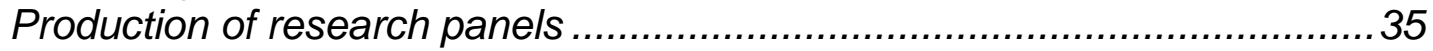

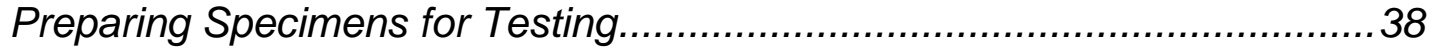

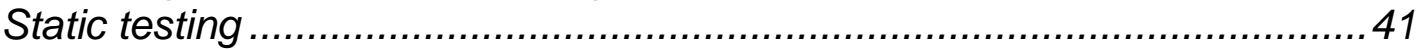

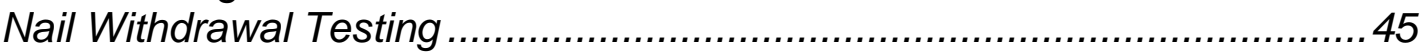

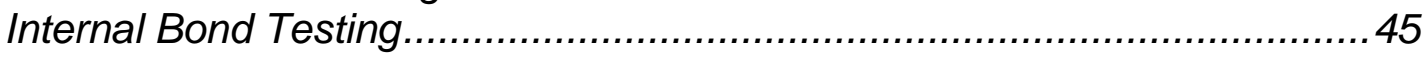

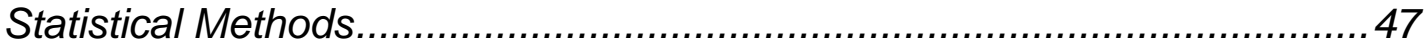

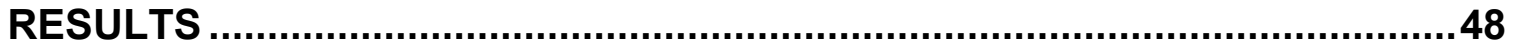

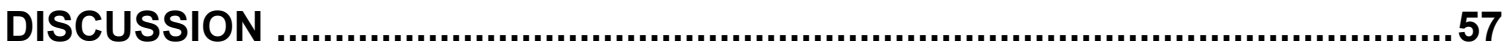

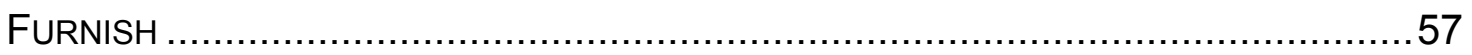

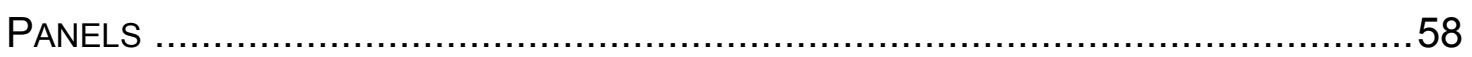

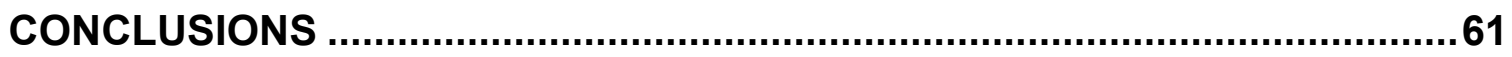

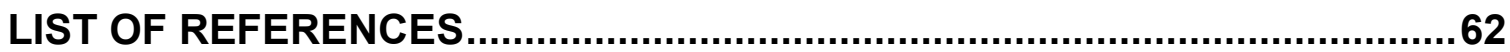

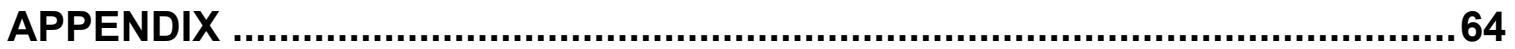

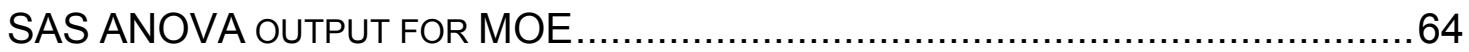

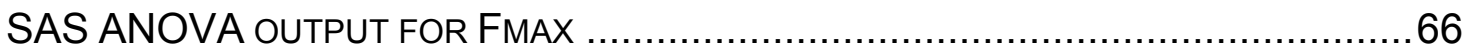

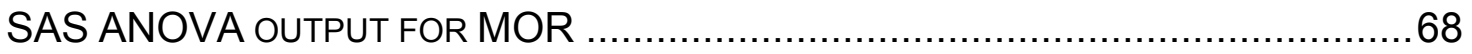

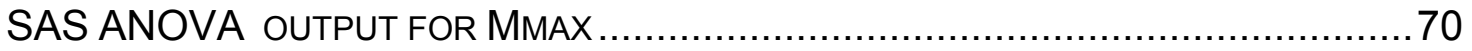




\section{List of Figures}

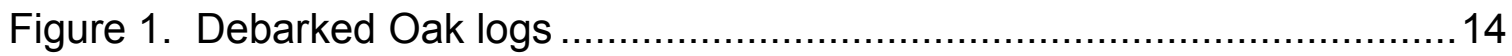

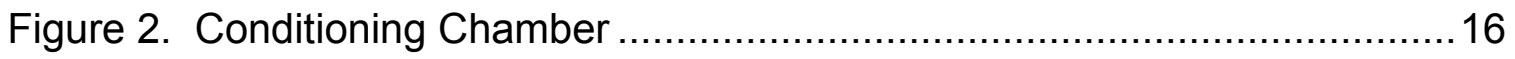

Figure 3. Screening Process for Oak Strands ...............................................18

Figure 4. Strand Weight Measurement …................................................20

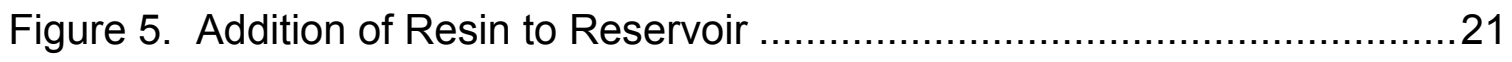

Figure 6. Resin outlet nozzles inside blender ............................................22

Figure 7. Extraction of resonated strands from blender .................................23

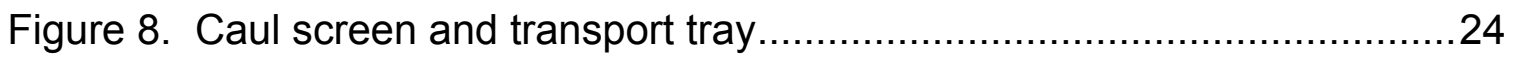

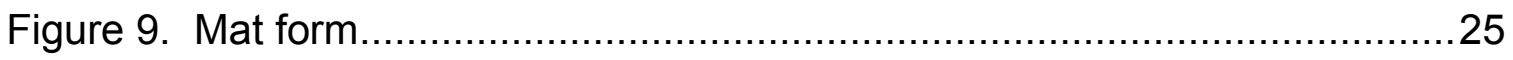

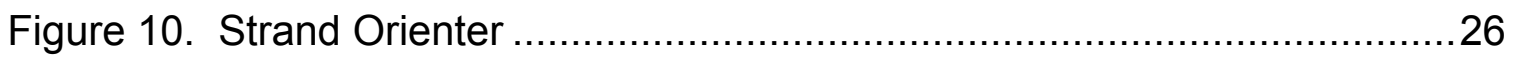

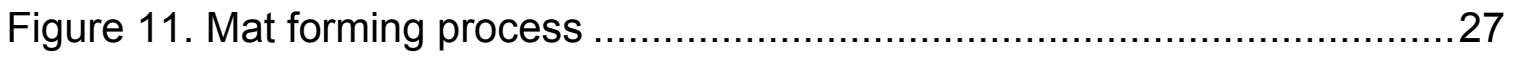

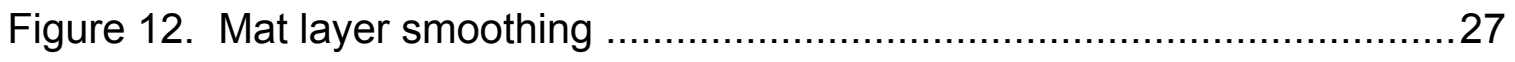

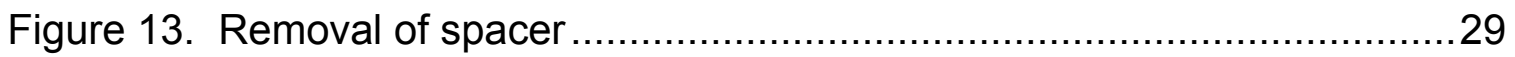

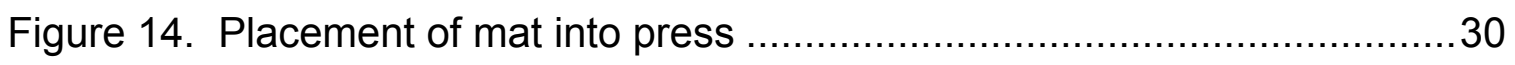

Figure 15. Press (left), Press control panel (right)....................................... 31

Figure 16. Internal bond testing specimens with brackets attached ..................33

Figure 17. Static Bending Test Setup ................................................... 42

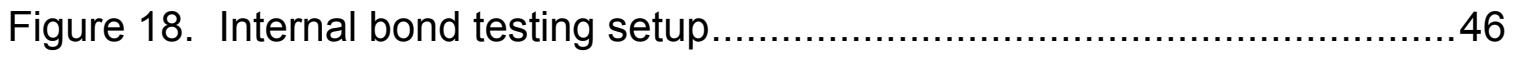

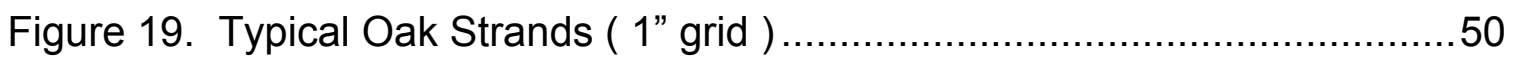

Figure 20. Oak strands created at Pallman Co. (1" grid )...............................51

Figure21. Distribution of Oak Strand Geometry .........................................52 
Figure 22. Scatter plot of panel density vs. MOE.

Figure 23. Area of low density .....

Figure 24. Reduced compaction with increase in oak percentage 60 


\section{List of Tables}

Table 1: Descriptive statistics for stranding trials .........................................48

Table 2. Significant Differences From ANOVA Results..................................54

Table 3. Summary statistics of the overall test results. ...................................56 


\section{List of Symbols / Nomenclature}

\begin{tabular}{|c|c|}
\hline$E_{A}$ & apparent modulus of elasticity (psi) \\
\hline$h$ & average height (in, cm) \\
\hline$a$ & average width (in, cm) \\
\hline$r^{2}$ & coefficient of determination \\
\hline$R$ & correlation coefficient \\
\hline$\Delta$ & deflection (in) \\
\hline$\rho$ & density $\left(\mathrm{g} / \mathrm{cm}^{3}, \mathrm{~kg} / \mathrm{m}^{3}\right)$ \\
\hline$Y$ & dependent variable \\
\hline$g$ & grams \\
\hline in & inch \\
\hline$X$ & independent variable \\
\hline$l$ & length of specimen (in, cm) \\
\hline$F$ & load (lbs) \\
\hline MOR & modulus of rupture (psi) \\
\hline$M$ & moment (in-lbs) \\
\hline$I_{X}$ & moment of inertia $\left(\mathrm{in}^{4}\right)$ \\
\hline lbs & pounds \\
\hline psi & pounds per square inch \\
\hline SWF & screw withdrawal force (lb) \\
\hline$S$ & second \\
\hline$S_{X}$ & section modulus $\left(\mathrm{in}^{3}\right.$ ) \\
\hline$L$ & testing span (in) \\
\hline$E_{T}$ & true modulus of elasticity (psi) \\
\hline$V$ & volume $\left(\mathrm{m}^{3}\right)$ \\
\hline
\end{tabular}




\section{Introduction}

Wood particle panels were first produced around the Second World War, as the availability of large timber became scarce in Europe. The idea gained great popularity due to the ability to convert small, low-grade timber into large useful panels (Kubler 1980)). In 1949, Armin Elmenforf first described a newly invented product, oriented strand board (OSB) and later patented his invention in 1965 (Elmendorf 1965). The patented product was called Waferboard and arrived on the market in 1970. Waferboard consisted of randomly placed thin flakes about $50 \mathrm{~mm}$ in length and width (Maloney 1977). As technology and knowledge of the process grew, Waferboard evolved to become OSB in the late 1970's. Since the time of its invention, research has been conducted on the effect of chip size, strand alignment, species mix, resin addition rate, density, and many other factors involved with the strength properties of OSB (Avramidis 1989). The result is the production of today's OSB panels which are far superior to their predecessors, Waferboard.

\section{What is OSB?}

OSB is a three layer structural panel product made from wood strands that are around .030 " in thickness, $0-2.5$ " in width, and range from $0-6$ " in length. Strands are usually made from pine, aspen, and various hardwood species. Ash (Fraxinus americana), locust (Robina pseudoacacia), and hickory (Carya spp.) are not used due to poor strandability. After stranding, strands are dried, screened, covered with resin (blended), formed into a three layer mat, and then 
hot pressed at approximately 400 degrees Fahrenheit. The screening process separates surface from core material, the surface material being made up of a higher percentage of larger strands. During the forming process, surface-layer strands are oriented parallel to the length of the panel while the core layer strands are oriented 90 degrees to the surface strands. The orientation of strands in this manner adds benefits to both the strength properties and to the shrinkage and swelling aspects of the panel. OSB strand orientation mimics the lay-up of veneer in plywood and OSB is also comparable to plywood in strength properties.

\section{Advantages of OSB}

OSB has many advantages relative to plywood. Strength properties comparable to plywood can be obtained using small, low quality, and relatively weak tree species (Illston 1994). Many of the these species such as pine, aspen, and yellow-poplar are also fast growing which makes OSB even more appealing for continuous large scale production. OSB utilizes small diameter stems which results in less logging residue and added profit for the logger and timber owner. OSB usually has less tendency to warp than plywood resulting in a much more uniform panel. Weak areas due to natural defects such as knots and splits are virtually eliminated due to the OSB manufacturing process. Also, OSB can be manufactured in sheets as large as $13 \mathrm{ft} . \mathrm{x} 26 \mathrm{ft}$., much larger than the plywood manufacturing process normally allows. Last, OSB is generally less expensive than plywood, approximately $25-50 \%$ less, while its nail and screw withdrawal strength and span rating are comparable with plywood (P.A.T.H. 2006). 


\section{Disadvantages of OSB}

The main disadvantage of OSB is irreversible thickness swell that occurs when exposed to extended periods of moisture. Plywood will also swell but not as drastically, then it dries back to original size more effectively than OSB. Recently, many OSB manufacturers began producing moisture resistant panels that perform much better than standard OSB panels. With continuous improvement, OSB panels may soon rival plywood even in moisture resistance. By taking some extra precautions during construction, exposure to moisture can be minimized and swelling problems eliminated. 


\section{Literature Review}

In the nearly three decades OSB has been produced, no significant changes have been made to the original panel makeup, although some alterations have been made to increase board properties. Currently OSB producers will increase panel density and resin to affect panel properties (Maloney 1993) however these changes will increase the cost of making the product. Both these methods are effective in adding strength but the increase is not overly impressive. With the recent explosion in demand for stiffness in floor systems many homeowners demand premium panels as opposed to standard grade. These premium panels can average as much as $100 \%$ more cost per panel.

It is highly probable that the demand for improved stiffness and density in OSB will continue into the future simply to meet the construction industry's demand for these superior characteristics. Finding a way to increase panel stiffness and even density without increasing manufacturing costs would benefit both the manufacturer and the consumer.

OSB is quickly overtaking plywood as the most widely used sheathing panel on the market today (Fisette 2005). Approximately 75 percent of all American homes currently under construction contain OSB wall, roof, and floor panels (Angelini et al. 2004). With the ability to utilize small, fast growing tree species, and tree tops, raw material can be procured with little difficulty. As large timber that is typically needed to produce plywood veneer becomes more difficult and more expensive to obtain, OSB shall certainly stay in high demand for years to 
come. With so many positive aspects, and the ability to engineer out virtually all negatives in the future, OSB is likely to remain a leader in its class.

Nearly 30 years of OSB application and manufacturing experience has led to many recent improvements in OSB panels. Edge swell is a problem that manufacturers have drastically reduced with two notable methods. The first is sealing the edges of panels with paints or waxes. This method works quite well on uncut panels but some panels will have to be cut. Once the panel is cut the advantage of edge sealing does not exist on the cut edge.

The second advancement is the production of so called new generation OSB panels (P.A.T.H. 2006). Standard OSB panels are made either with liquid phenol formaldehyde (LPF) resin on all strands or with LPF on surface strands and Poly(diphenylmethane diisocyanate) (pMDI) resin in the core. These LPF panels require a high amount of heat and pressure for bonding to occur. High pressures create dense panels that are prone to swell when exposed to moisture. New generation panels, using $100 \% \mathrm{pMDI}$ resins can accomplish bonding without the need for extreme heat and pressure. While LPF resin primarily forms mechanical bonds with wood, pMDI resin forms covalent bonds which are stronger and can produce improved structural performance (TECO 2005). Using pMDI resin, results in a lighter weight panel that is less prone to swelling.

These new generation panels are capturing the sub-floor market by promising increased durability, better thickness tolerances, and offering longer warrantees against defects such as delaminating and edge swell. One company in particular 
is currently offering a line of new generation OSB flooring with a 90 day guarantee against edge swelling under any moisture conditions and a 50 year limited warranty (Building Online 2005).

As with most improvements, there are drawbacks associated with the use of pMDI resins. pMDI is considerably more expensive than LPF, but less pMDI is required. Since pMDI bonds to metal surfaces, release agents must be applied to caul screens and press platens. Due to health hazards associated with pMDI exposure, extra precautions including monitoring of the atmosphere and use of respirators must be taken at all times pMDI is in use. This is a major drawback especially for the manufacturer who is ultimately responsible for the safety of employees. A unique storage system must be in place for pMDI because exposure to atmospheric moisture can cause premature curing (TECO 2006). Also, because pMDI is a relatively recent (15 years) improvement, OSB performance under extended periods of loading is unknown.

Adding resin, whether it is pMDI or LPF, can benefit panel properties including increased stiffness, durability, load tolerances, and decreased edge swelling. Adding resin is the key to many of the new specialty flooring panels. Experimentation has also shown that thinner, longer strands improve many panel strength properties by providing more surface area contact and improved load transfer (Angelini et al. 2004)

OSB has proven its ability to be used in many different applications such as commodity sheathing. There are areas of the world where insects such as 
termites cause major degradation of wooden structures. To combat this problem OSB treated with borates or copper based preservatives is highly effective as an insect and decay resistant material. The same treating process also adds resistance to moisture, mold, and fire (Angelini et al 2004).

Two new OSB products have recently emerged but their popularity remains to be seen. Thermally reflective overlaid OSB is a sheathing product in which foil is overlaid on OSB panels. Foil creates a radiant shield that significantly reduces thermal transfer through a roof. Benefits include cooler attic temperatures, longer shingle and heating/cooling system life, improved heating in winter and reduced energy bills. Another product is called overlaid OSB and the idea behind it is to create a basement flooring system. OSB tiles glued to polyethylene cleats, high density polystyrene, or corrugated plastic are placed on the concrete floor. These tiles are neither nailed nor glued down. The result is airflow between the cleats and the OSB floor which deters mold and moisture problems. Voids also allow drainage towards preinstalled floor drain(s). Several types of flooring can be installed over this floor system including: engineered hardwood, vinyl, laminate, etc.

Other new OSB products include siding and concrete forms. OSB siding is coated with a paint-based covering that mimics the appearance of cedar grain. The siding is weather and insect resistant due to resin saturation, edge and groove coating and borate treatment. OSB again shows an ability to adapt and gain a share of newly developed markets or as a new product in existing 
markets. Although many builders already use OSB for concrete forms, some formwork demands a smoother surface than standard OSB can provide. For this reason a series of OSB specifically designed for concrete forming has been created. These specialty panels have added resin for strength and durability to withstand multiple pours. The panels also have a smooth, medium density overlay to compete with plywood and smoother fir form material.

In addition to standard sheathing type applications, OSB has also taken on tremendous growth in serving as a component in many engineered wood products and structural systems. Many structural systems are sold in packages containing all the necessary materials to complete the job. For instance, at least one manufacturer is advertising an engineered stair system that utilizes OSB for treads, stringers, and risers. This system is claiming to eliminate squeaks and provide sound structural integrity. Engineered floor systems are probably the largest secondary user of OSB today. Every component of the system contains OSB including the webs of engineered I-joists, OSB rim board, and OSB floor sheathing. I-joist webs are usually $1 / 2$ " OSB, but the rim boards are $11 / 8$ " or 1 $1 / 4 "$ in thickness. This added thickness enables rim joists to endure heavy vertical loads from the walls above. Along with expanding OSB's market, engineered floor systems provide the consumer a guarantee of performance not included with typical solid wood construction.

When thinking of OSB, most people picture relatively thin sheathing type material. A product that is changing the shape of OSB is oriented strand lumber 
(OSL). Oriented strand lumber is manufactured basically the same as OSB. The differences in OSL are that longer strands are used, strands are all oriented in the same direction, and more resin is used to create thicker dimensional members. OSL is not yet widely used for structural applications but mostly for framing members in upholstered furniture and similar furniture components (Angelini et al. 2004)

There are also a few new products that utilize non-wood material with OSB to add strength in some form or another. Recent hurricanes have sparked the interest of many to combat home destruction caused by high winds. One product in particular that appears to have enough momentum to push it into production is advanced oriented strand board (AOSB) (Davids 2005). While examining hurricane damage, researchers discovered that panel edges and nail pull through were weak areas in OSB wall sheathing. With this finding, came the idea of AOSB being developed at the Advanced Engineered Wood Composite Center housed at the Universtiy of Maine. AOSB is basically standard OSB with a layer of fiber reinforced polymer (FRP) sandwiched between the layers of wood along the panel edges. This creates a reinforced nailing area and tests show great improvements in shock absorption when compared against standard OSB.

The many new advancements in OSB seem to have overshadowed the original advantage of OSB, utilizing low grade material while creating a high quality product. Since production of OSB began, certain tree species have been preferable for stranding. With a large supply of preferred species, any effort to 
utilize less desirable species has not been a priority. As with any other natural resource, the highest quality and most easily accessible supplies are used first. Though there is no immediate danger of eliminating these supplies, slowing the extraction of particular species could only aid in a sustainable supply of these optimum OSB species. Also, utilizing low quality stems of species that are not currently used in OSB production could drastically decrease the percentage of logging residue.

Grushecky et.al. (2006) found that there is approximately five tons of oak residue per acre left after the harvest each year in southern West Virginia. Apply these averages statewide and that equates $1,125,000$ tons of low quality oak available each year in West Virginia. A standard OSB mill utilizes 730,000 tons annually, which could easily be provided by this amount of oak. Findings of this study, along with the previously mentioned research, lead us to persue this project. The objectives of this research may be found in the following section.

\section{Objectives}

This research was performed to determine the feasibility of using oak strands in oriented strand board (OSB). Currently, only a small percentage of oak is used in OSB, largely due to the inability to produce geometrically suitable strands from oak. Furthermore, the quantity that may be used in a panel without sacrificing panel performance has not been determined. The main objective of this research was to assess the limitations of utilizing oak species in OSB panels. 
This main objective consisted of the following sub-objectives:

- Making acceptable strands from the oak species;

- Testing various resin addition rates to find optimal rate;

- Determine the effect of compaction ratio on overall panel quality.

To accomplish these objectives, the following Materials and Methods were used. 


\section{Materials and Methods}

During this research, five combinations of strand material were used in the production of OSB panels.

\section{Materials:}

1. mixed hardwood OSB furnish

2. $25 \%$ oak furnish and $75 \%$ mixed furnish

3. $50 \%$ oak furnish and $50 \%$ mixed furnish

4. $75 \%$ oak furnish and $25 \%$ mixed furnish

5. $100 \%$ oak furnish

Standard mixed hardwood furnish was obtained from an OSB mill in Heaters, WV. This mix usually consists of: yellow-poplar (Liriodendron tulipifera), red maple (Acer rubrum), sugar maple (Acer saccharum), sourwood (Oxydendrum arboretum), sassafras (Sassafras albidum), sycamore (Platanus occidentalis), black gum (Nyssa sylvatica), American beech (Fagus grandifolia), up to 9\% pine (Pinus spp.). Hardwood species excluded include: black locust (Robinia pseudoacacia), white ash (Fraxinus Americana), hickory (Carya spp.), Elm (Ulmus spp.), black walnut (Juglans nigra) and oak (Quercus spp.). The furnish consisted of two categories, surface strands and core strands. Surface and core strands are separated by the mill's screening process. Surface strands include 
all strands that do not fall through a screen with $3 / 4$ " square openings. All other strands are deemed core material. Due to this process, core strands include a much higher percentage of smaller pieces which aid in compaction of the core layer, while surface strands contain a higher percentage of larger strands.

\section{Methods}

\section{Obtaining Oak Strands}

Since oak does not typically strand well using a standard strander setup for mixed hardwoods, measures were taken to ensure that quality oak strands could be produced under the worst possible conditions, such as frozen wood. Two oak trees were harvested in winter conditions. Six logs were bucked out of these trees, three chestnut oak (Quercus prinus) and three northern red oak (Quercus rubra) logs. The logs were six feet long and averaged 10" in diameter. Debarking was performed using a drawbar and logs were immediately wrapped in plastic to reduce moisture loss. Debarked logs can be seen in figure 1. 


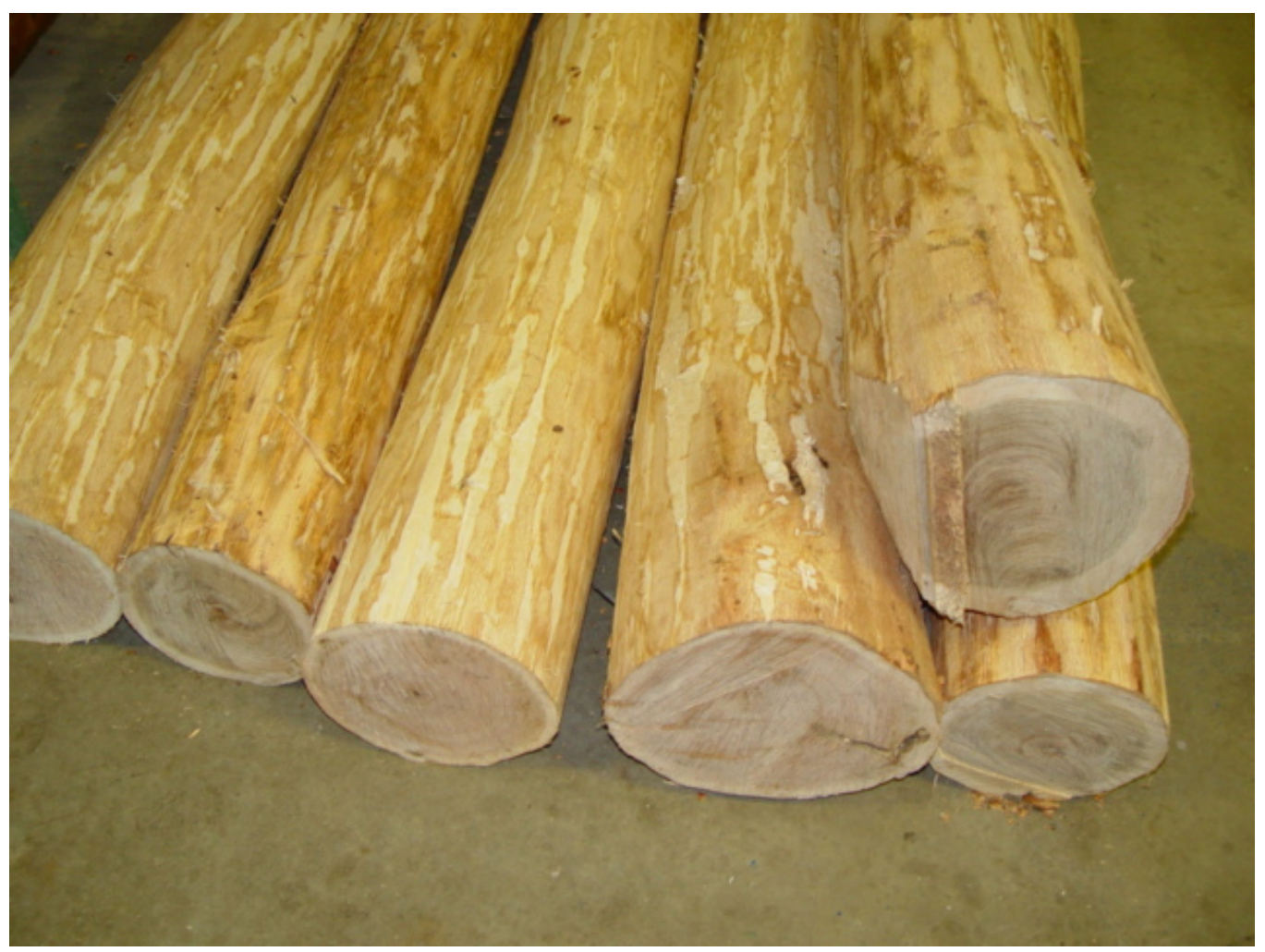

Figure 1. Debarked Oak logs

The logs were then shipped to the Pallmann Company, a strander manufacturer in Germany, where strands were to be produced. Logs were stored outside where temperatures were reported to be around 30 degrees Fahrenheit To combat problems like splintering, typically associated with stranding oak, researchers at Pallmann experimented with their laboratory strander setup using relatively dense European species before stranding our logs. After adjusting some strander variables such as knife angle, knife projection, and cut time, Pallmann was producing highly desirable strand geometry with our oak logs. Details of the final setup remain proprietary to Pallman and cannot be disclosed. At the time of stranding, the logs were at approximately $35 \% \mathrm{MC}$. Strands were produced, dried in a conveyor system, and shipped back to West Virginia University. 
During this initial experiment, five bags of both red and chestnut oak were shipped back to the university. Individual bags weighed approximately $15 \mathrm{lbs}$. and contained the produced strands from one complete strander stroke. With the use of Weyerhaeuser's BM\&M screen classifier, each bag was classified by separating the strands into eight size classifications: $11 / 4 ", 1$ ", 3/4", 1/2", 1/4", 3/16", 1/8", and the bottom pan with no holes. Strand thickness was also measured using a pneumatic digital caliper accurate to .001 ". Thickness measurements were taken on 50 randomly selected strands from the $1 \frac{1 / 4}{4}$ tray. Last, the weighed average width and length was determined for each bag. Weighed averages were calculated by weighing each tray containing strands after the shaking process was completed. The percentage of the total strand mass in each tray was then calculated.

For instance, if the total strand mass was $2.21 \mathrm{lbs}(1000 \mathrm{~g}$.) and the 1" tray contained 1.10lbs (500g.), the 1 " tray contained $50 \%$ of the strand mass. Therefore, if a total of 50 strands were measured to determine average length and width, 25 strands from the 1" tray were measured.

After the results from the initial trial were analyzed, arrangements were made to repeat the trial. Repeating the trial with acceptable results would ensure that the procedure is replicable. For the second trial, white oak logs harvested in Germany were stranded. Anatomically, reviewed literature showed no differences between German and American white oak. Strands from the second stranding 
trial were also sent back to the university and analyzed in the same manner as the first trial. All strands were held in a conditioning chamber at $6 \%(\mathrm{MC})$.

Upon completion of strand analysis, preparations were made to begin the process of panel production. Arrangements were made to pick up standard mixed hardwood surface and core material from the Heaters, WV OSB mill. Dried strands were dumped directly out of the production process into portable containers, containing approximately 1 cubic yard in volume. Two boxes were obtained, 1 surface and 1 core. To reduce (MC) changes, lids were fastened to the boxes before transporting them to the University. Strand boxes were immediately placed in the conditioning chamber upon arrival at the university (Fig. 2.)

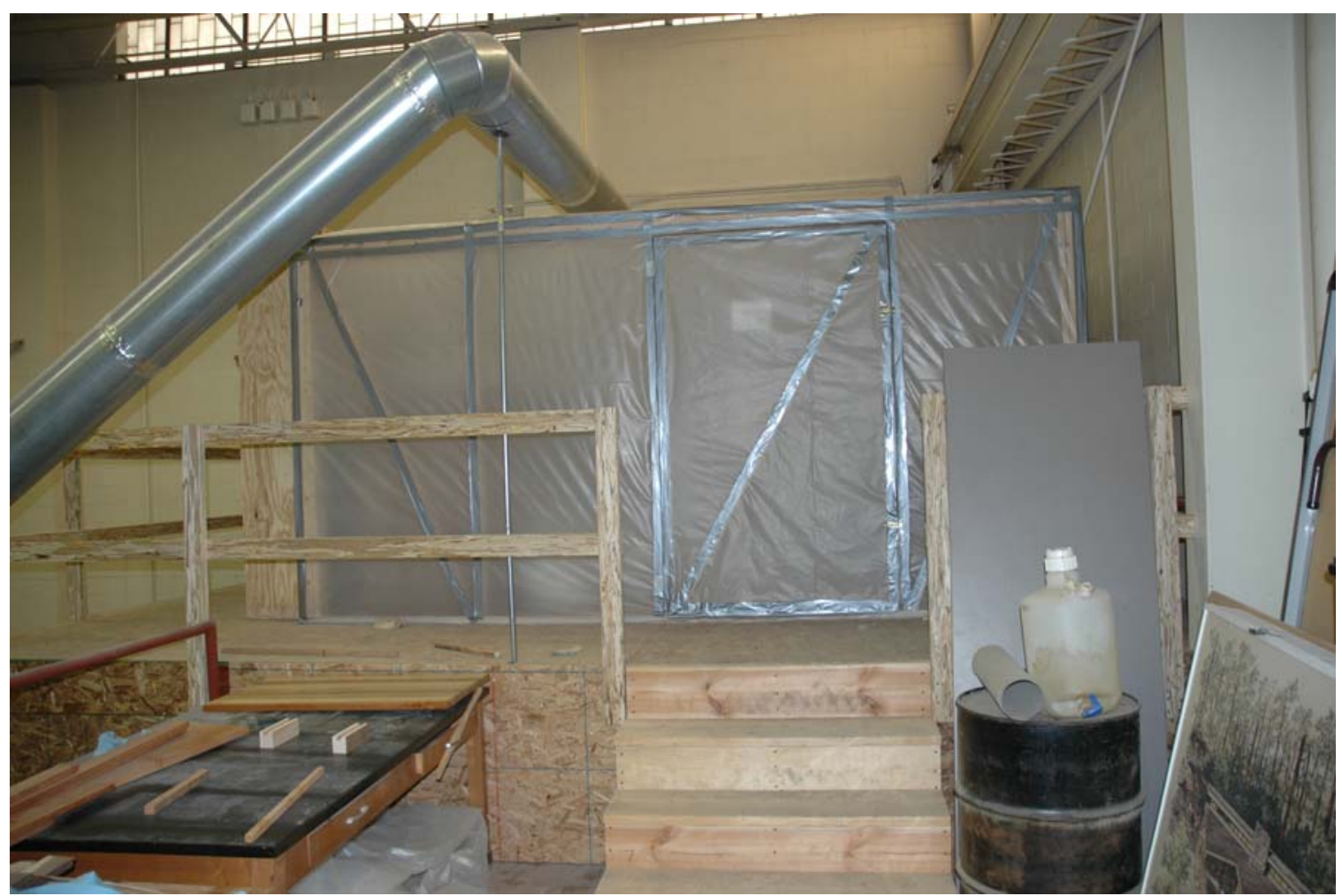

Figure 2. Conditioning Chamber 
Oak strands were also stored in the conditioning chamber but were not yet separated into surface and core material. Since it was impractical to place the oak strands in the OSB mill's screening process, another method of screening was developed. A shallow wooden frame approximately 25 "x25" and 4" in depth was built and a wire mesh was stretched and attached across the bottom of the frame. Two handles were attached to the top of the frame so that shaking could be performed once strands were placed on top of the wire mesh made up of 1" square openings. Oak strands were then screened and separated into surface and core material. Screening consisted of placing strands on top of the wire mesh and manually shaking the apparatus for approximately 20 seconds. This process is illustrated in Figure 3. 


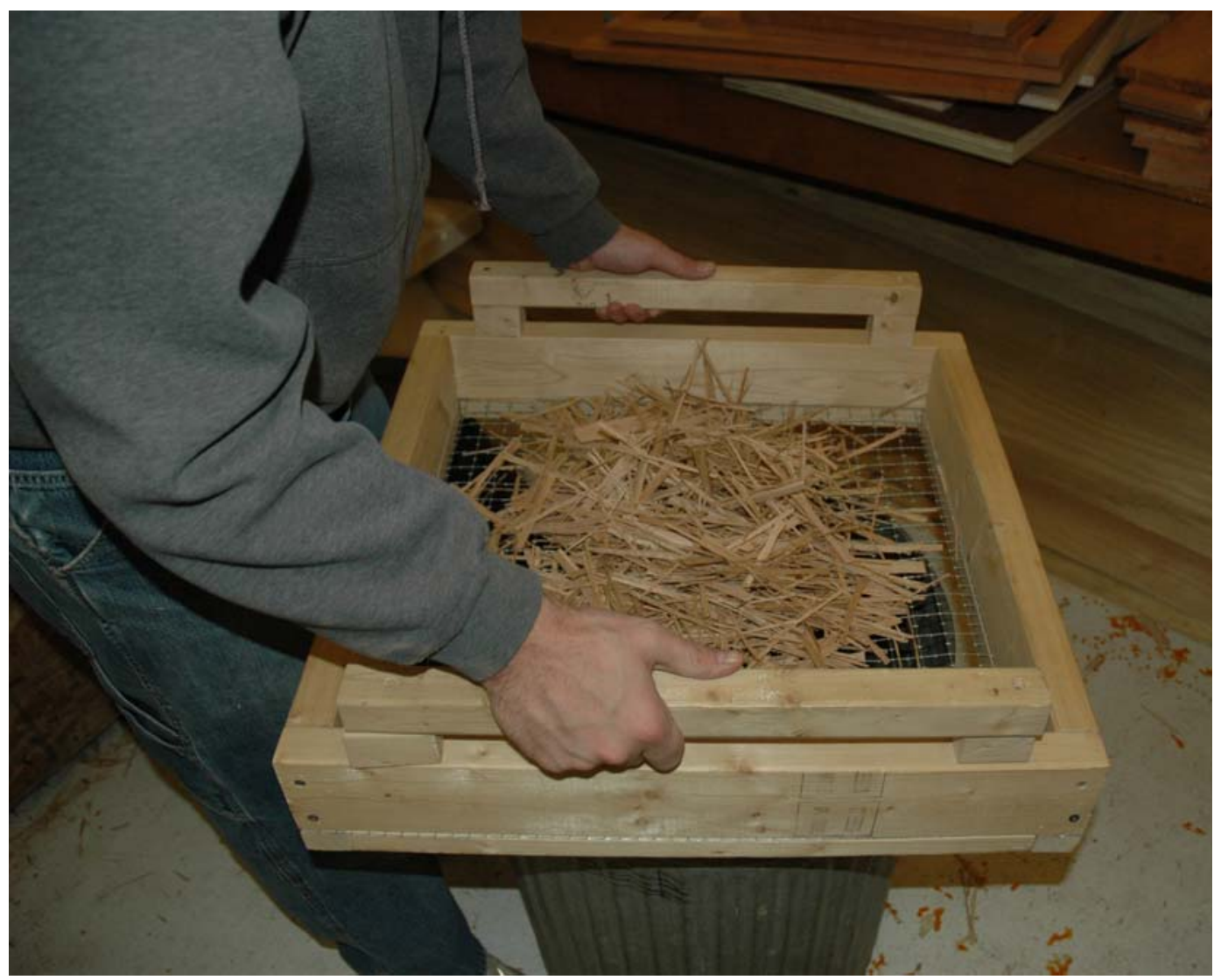

Figure 3. Screening Process for Oak Strands

Strands that fell through the screen were deemed core material and those that remained on top were considered surface material. This method was not as efficient or thorough as industry's standards of quality controls but was sufficient for the purposes of this study. These strands were then placed into bags labeled as surface or core. Once screening of the oak was completed strand bags were once again stored in the conditioning chamber. The last material obtained in preparation of panel production was liquid phenol formaldehyde (LPF), from Georgia Pacific Resins. 
Panel production was ready to begin, but first the amount of available material and number of panels to be produced was determined. From previous panel production, the approximate dimensions of pressed panels were known to be 27 in. $x 27$ in. $x 0.719$ in. From these measurements, panel volume was calculated. The target density was approximately $43 \mathrm{lb} / \mathrm{cubic}$ foot (Weyerhaeuser cooperating mill 2006). From these known measurements, density calculations were performed and revealed that approximately $13.23 \mathrm{lbs}$. (6000g.) of resinated strands were required for each panel. Resinated strands is a term used in industry to describe post blended strands with resin.

Oak strands were the limiting material in the production of panels due to the time and cost necessary to acquire more oak strands from Germany. After weighing all of the oak surface and core strands, it was determined that six panels of each treatment could be produced. Since the supply of oak strands was limited, it was apparent that wasting oak strands would be detrimental to this research. Therefore, several trial panels were initially made using standard furnish from the OSB mill.

\section{Producing Trial Panels}

The desired amount of strands was weighed on a scale accurate to +/- $2.2 \times 10^{-6}$ lb. $(.001 \mathrm{~g})$, as shown in Figure 4. 


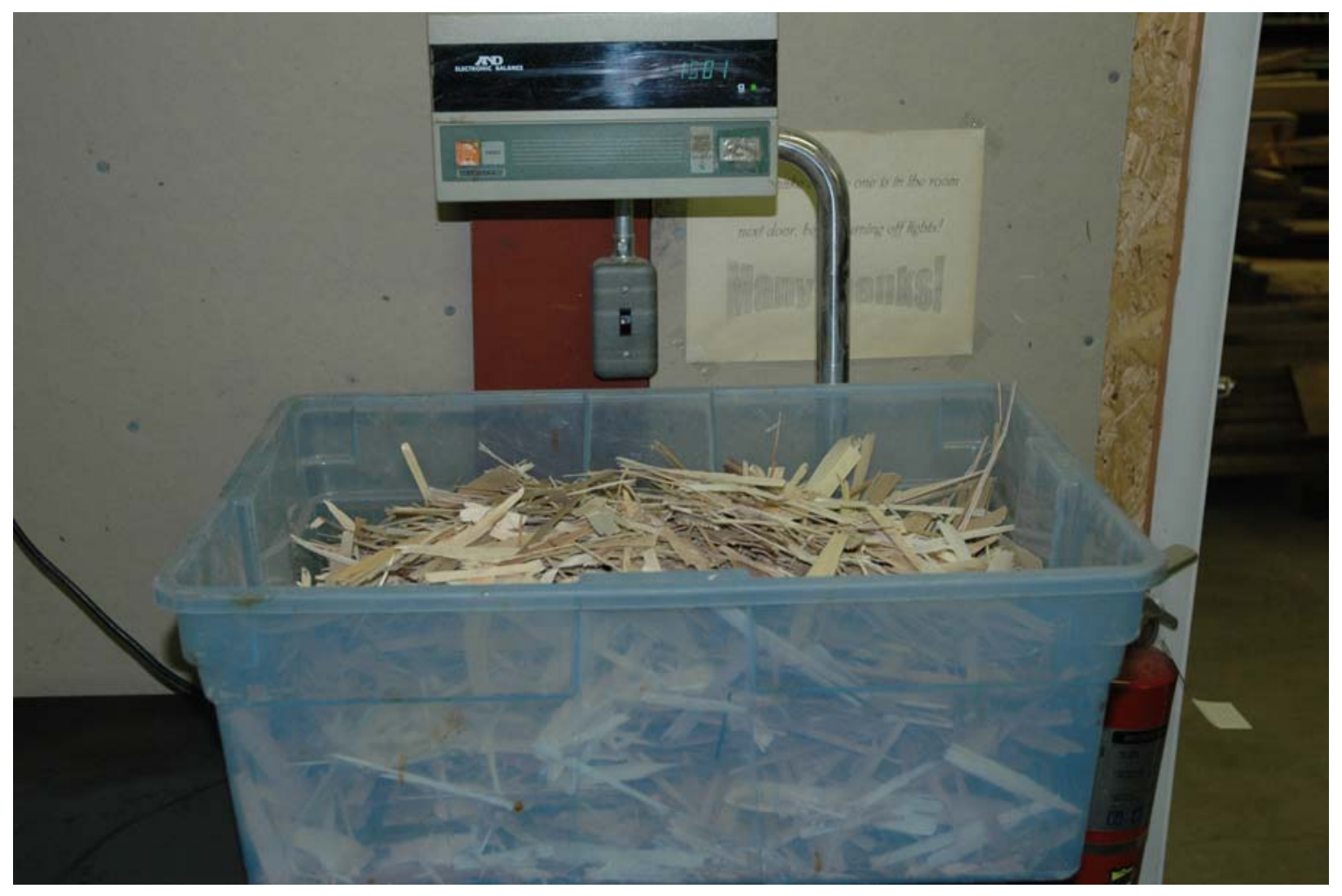

Figure 4. Strand Weight Measurement

In order to obtain a density of $43 \mathrm{lb} / \mathrm{ft}^{3}$ in a $27 \mathrm{in.} \times 27 \mathrm{in} . \times 0.719$ in. panel, 13.23 lb. (6000g.) of resonated furnish was used in panel formation. $6.615 \mathrm{lb} .(3000 \mathrm{~g}$.) of resonated surface furnish and $6.615 \mathrm{lb}$. (3000g.) of resonated core furnish were necessary for each panel. LPF resin was also weighed out on a scale accurate to $+/-2.2 \times 10^{-6} \mathrm{lb}$. (.001g.). A $10 \%$ resin addition rate was settled on for the final panel production. The weight of resin added to strands during blending equated to $10 \%$ of the weight of strands in the blender. During the production of trial panels, resin coverage was tested using a spray solution of bleach and water on blended strands. This solution reacts with the LPF and turns purple where resin is present, otherwise the thin coat of resin is invisible to 
the naked eye. Adding $10 \%$ resin addition resulted in excellent coverage when strands were tested in this method.

With our blending setup, approximately $6.615 \mathrm{lb}$. (3000g.) of strands per batch proved to be an optimal amount to obtain optimal resin coverage and maximize production. When over $6.615 \mathrm{lb}$. (3000g.) was blended, resin coverage suffered due to inadequate mixing and exposure of strands to resin spray. Since $6.615 \mathrm{lb}$. (3000g.) of strands were blended per batch, .662 lb (300g.) of LPF resin was weighed and added to the resin reservoir mounted to the side of the blender frame for each batch (Figure 5.).

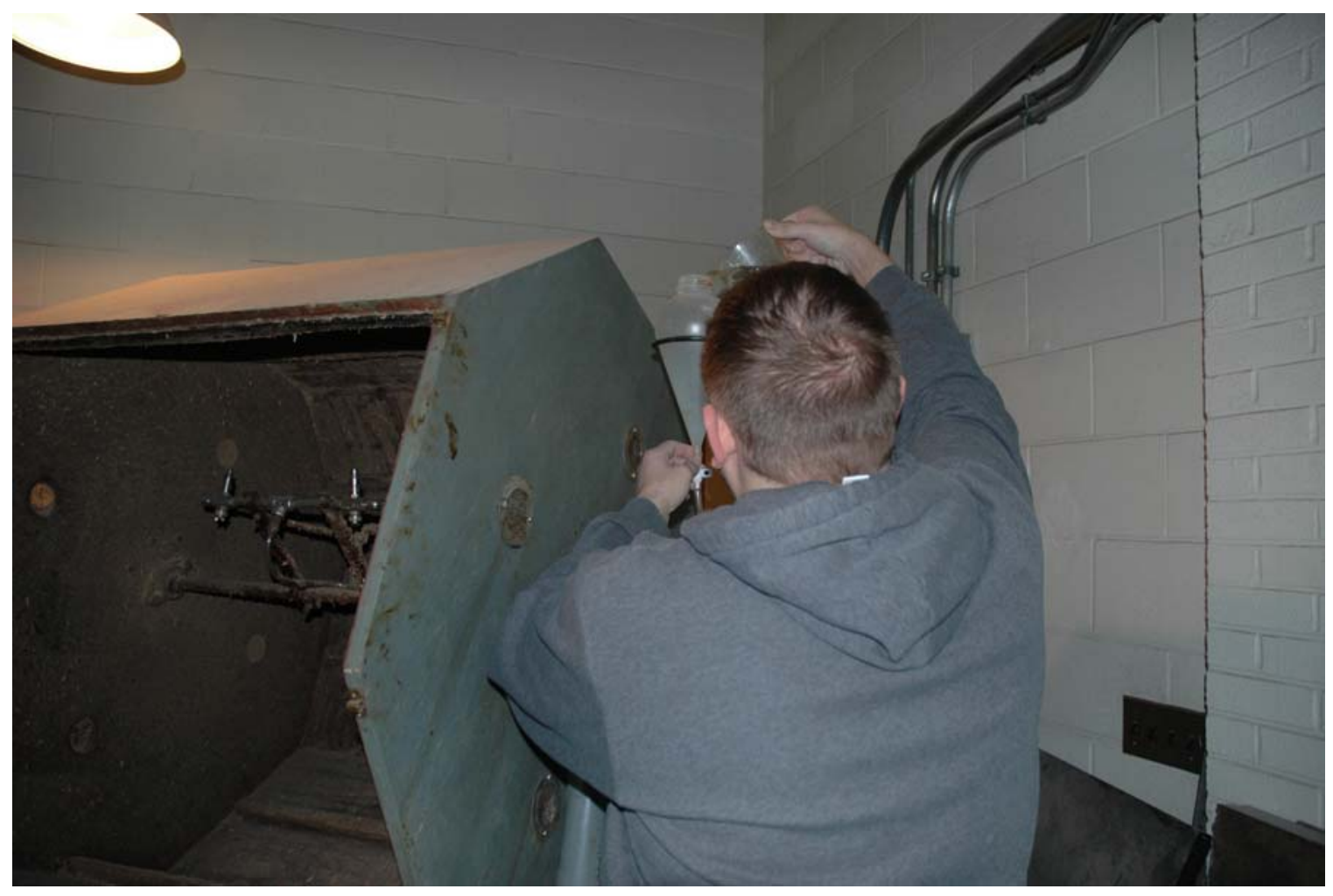

Figure 5. Addition of Resin to Reservoir 
At this time the blender motor was activated which began rotation of the blender. With blender rotating, air pressure was immediately turned on and adjusted to approximately $18 \mathrm{psi}$. Air pressure atomized the resin at the outlet nozzles inside the blender, shown in figure 6 .

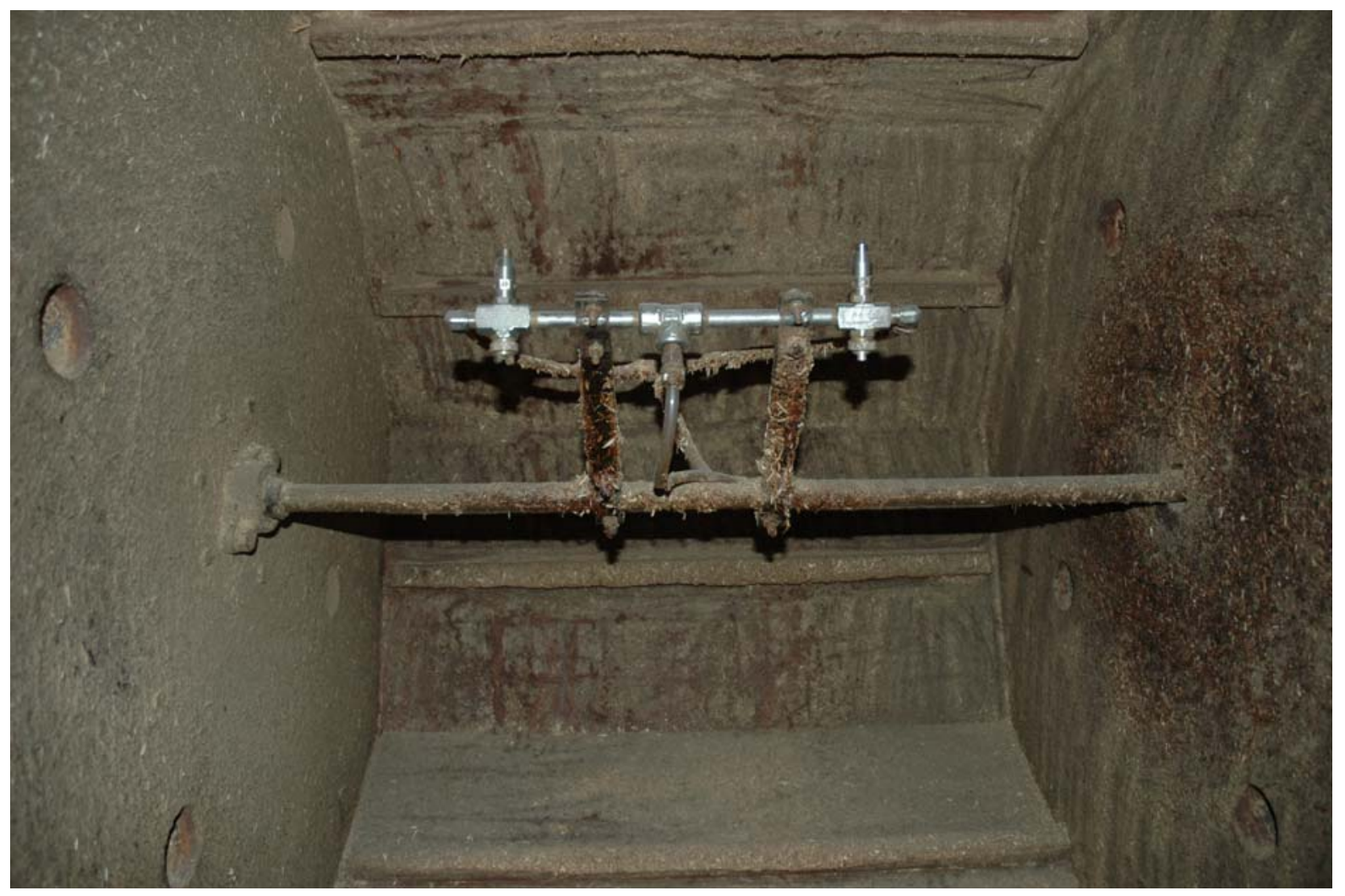

\section{Figure 6. Resin outlet nozzles inside blender}

Decreasing the resin particle size by adding air pressure resulted in a more uniform coating of resin during the blending process. The resin pump was turned on, because of critical reasons, as a very last act. Turning on the pump before the blender was rotating resulted in resin coverage on only the exposed surface of stationary strands. Turning on the pump, before air pressure was added, causes a stream or droplet effect inside the blender, which resulted in excess 
resin on a small percentage of strands and none on most. With the resin flowing, all aspects of the blending operation remained on until the resin reservoir was empty, approximately 2 minutes. Once empty, all functions were turned off.

With the blender at a zero energy state, resinated strands were extracted (as shown in Figure 7.) and placed into a plastic tub labeled with the type of furnish. In order to maintain separation among furnish types, only one type could be blended at a time and the interior blender walls are thoroughly scraped with each extraction of strands. After resinated strands were extracted, time before pressing did not exceed two hours due to resin manufacturers' recommendation.

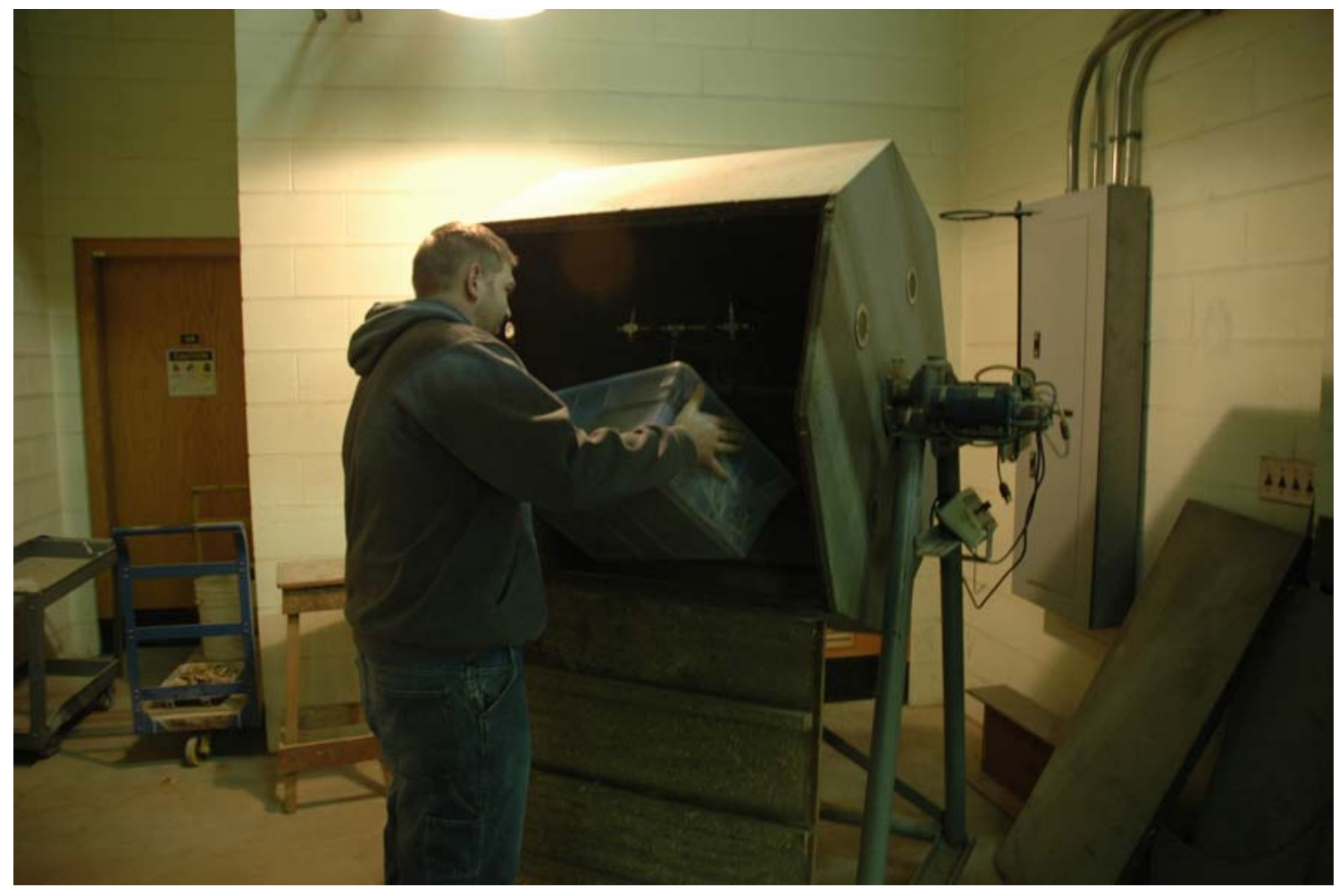

Figure 7. Extraction of resonated strands from blender 
When all necessary furnish for panel formation was blended, the forming process began. A standard forming setup was used for all panels produced in this research. A 30"x30" wooden tray served as the subsurface for the forming process, while a 30 " $\times 30$ " caul screen was placed on top of the tray, shown in Figure 8. The mat form was placed on top of caul screen

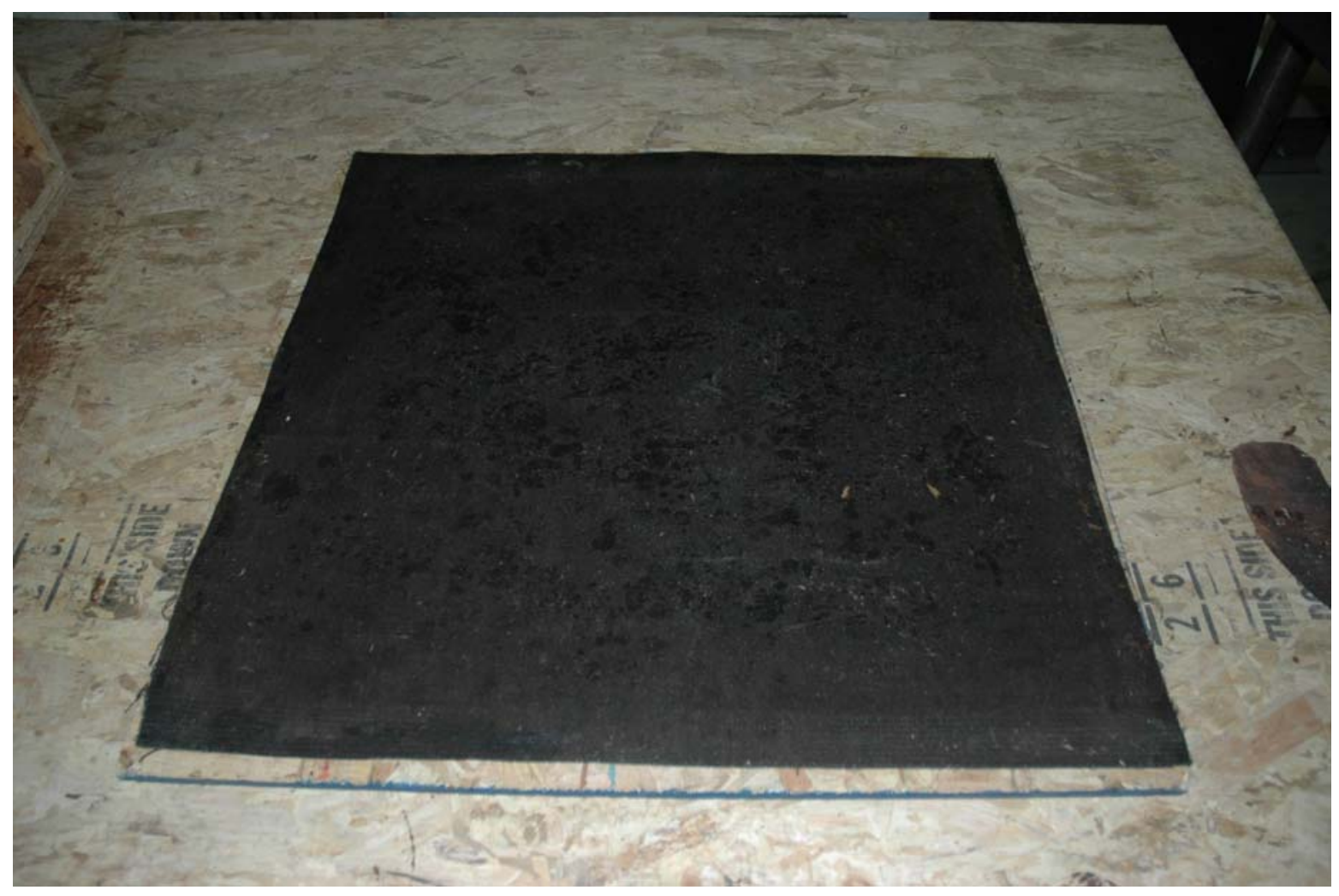

\section{Figure 8. Caul screen and transport tray}

Caul screen is a thin mesh metal screen that allows transport of the loose mat into the press while remaining under the mat during pressing. After pressing, the caul screen and panel are easily separated. In industry, the mat is formed on and transported through the pressing process on a caul screen carried by a conveyor type system. The mat form was a 27 in. $x 27$ in. $x 8$ in. wooden frame 
with no top or bottom, used to contain and shape the mat during forming. (figure 9.)

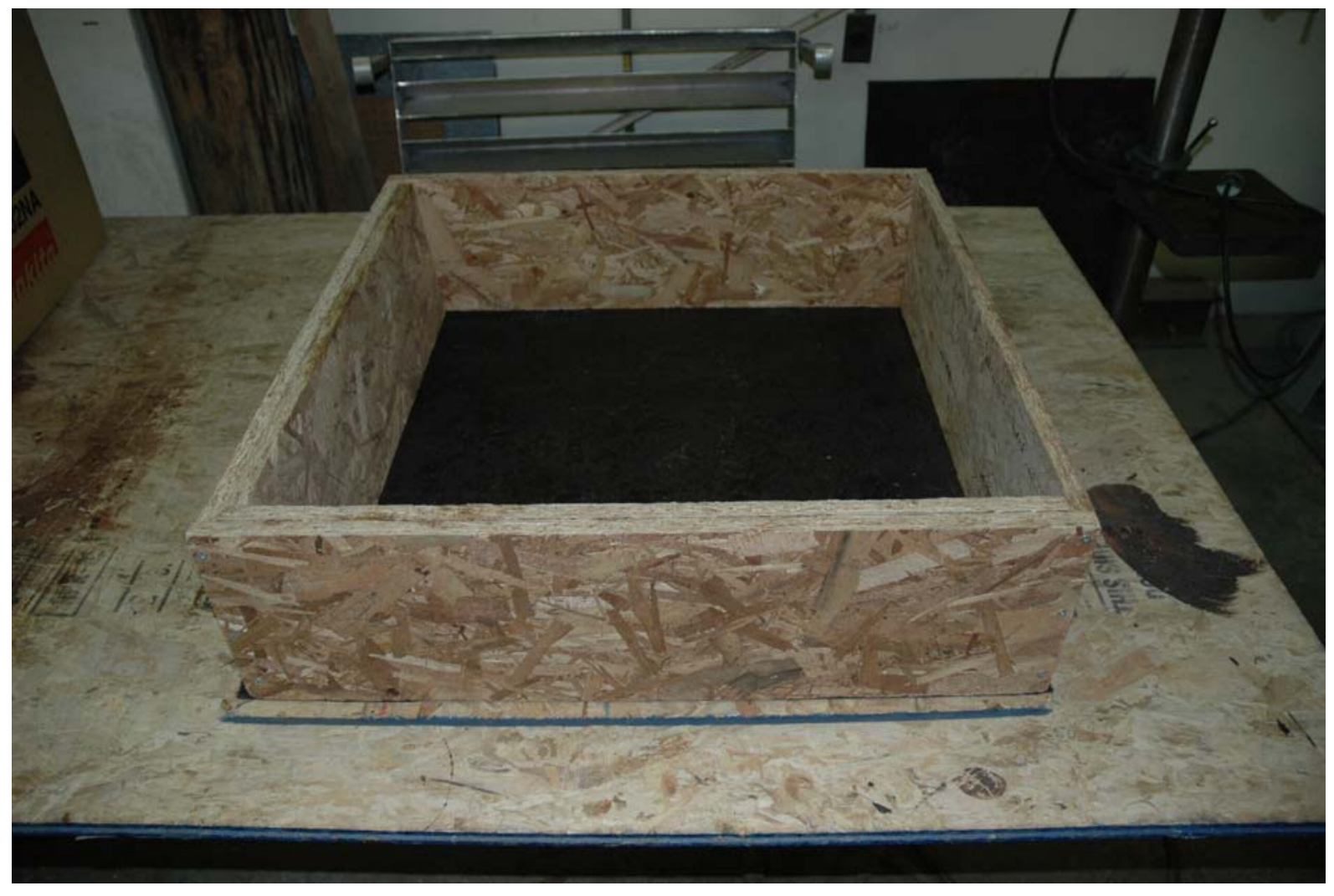

\section{Figure 9. Mat form}

With the form in place, formation of the first surface layer began. As previously mentioned, panels contained $6.615 \mathrm{lb}$. (3000g.) of resonated surface furnish and $6.615 \mathrm{lb}$. (3000g.) of resonated core furnish. Since there are two surface layers, they each contained $3.308 \mathrm{lb}$. (1500g.) of resonated strands. The amount of resonated strands needed was weighed before forming each layer. $3.308 \mathrm{lb}$. (1500g.) of surface furnish was weighed, and a strand orienter was placed over the mat form. The strand orienter was an aluminum frame on legs that consisted of long funnel-like slots running parallel with each other. See figure 10. 


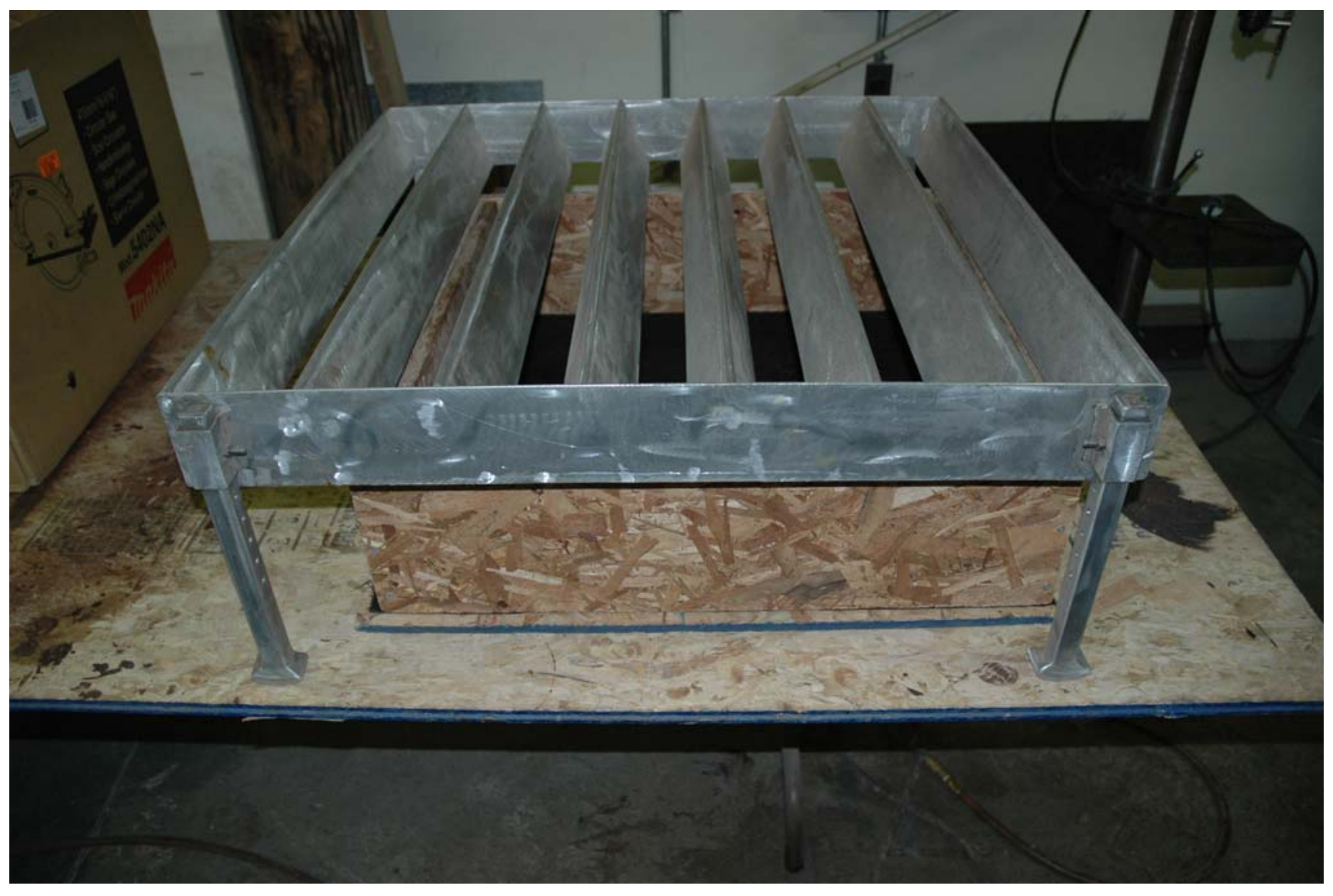

\section{Figure 10. Strand Orienter}

Legs elevated and held the orienter above the mat form so that when strands were dropped through the orienter they fell directly into the form. Since a majority of strands were $4-5$ in. in length and the slots were only $17 / 8 \mathrm{in}$. in width, strand alignment was significantly improved by using the orienter. Once first surface layer strands were dropped through the orienter, (see figure 11.)the orienter was removed so that high and low areas in the newly placed layer could be manually smoothed (Figure 12.). This process was not perfect but aided in maintaining consistent material thickness throughout the formed layers which reduced high and low density areas in the panel. 


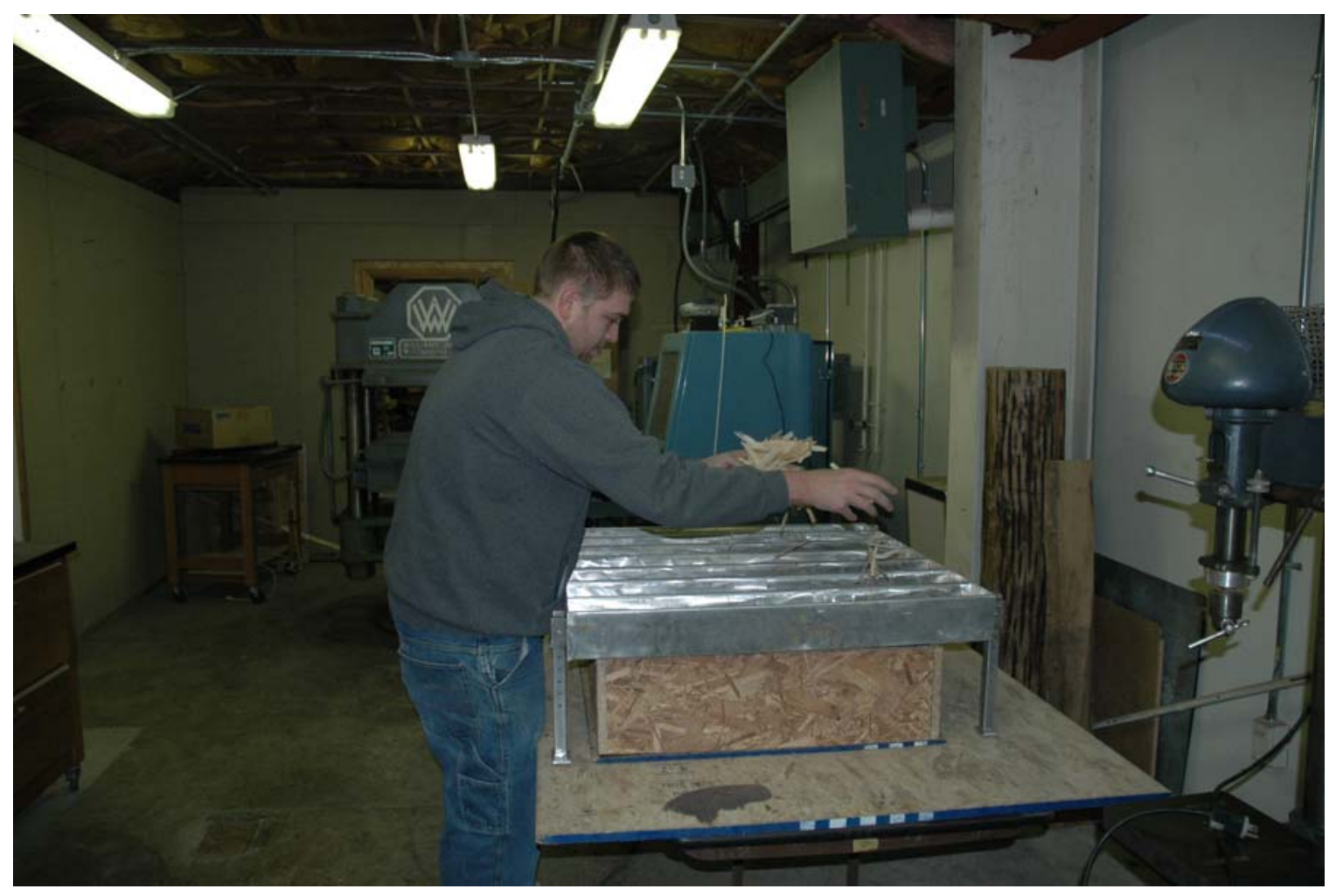

Figure 11. Mat forming process

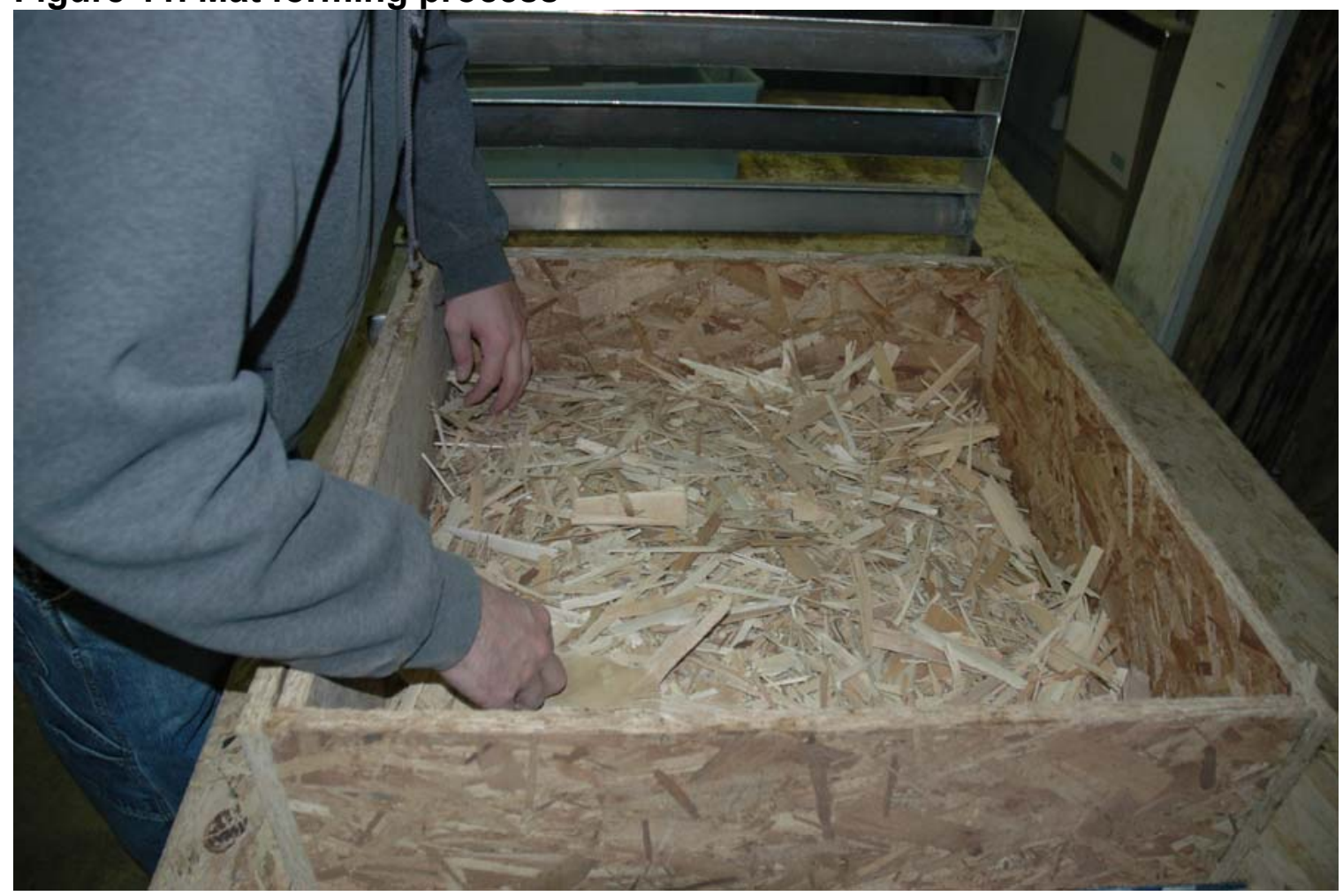

Figure 12. Mat layer smoothing 
Next, $6.615 \mathrm{lb}$. (3000g.) of core material was weighed in preparation of forming the core layer. In industry, two core layers are formed; both oriented in the same direction. In the research panels, the core was formed as a single layer. The significance of two layers in industry is that each forming head lays down an equal amount of material on the caul screen, thus allowing the process to move at a constant rate. For this research, forming two core layers would have been a formality that would have had no effect on panel structure. Therefore, the orienter was rotated 90 degrees from the surface orientation and the core was formed in one layer using $6.615 \mathrm{lb}$. (3000g.) of resonated core furnish. Next, the orienter was removed and the core layer was smoothed for thickness. Last, $3.308 \mathrm{lb}$. (1500g.) resonated surface material was weighed in preparation of forming the second surface layer. The orienter was once again rotated 90 degrees to match the alignment of the first surface layer. Strands were dropped through the orienter and the second surface layer was smoothed for thickness. This completed the formation of a four-layer OSB mat.

The mat form was removed in preparation for placement of the mat into the hot press. The first step in removing the form was to lift out a single layer spacer that had been added to one side of the forms interior earlier in the process. See figure 13. 


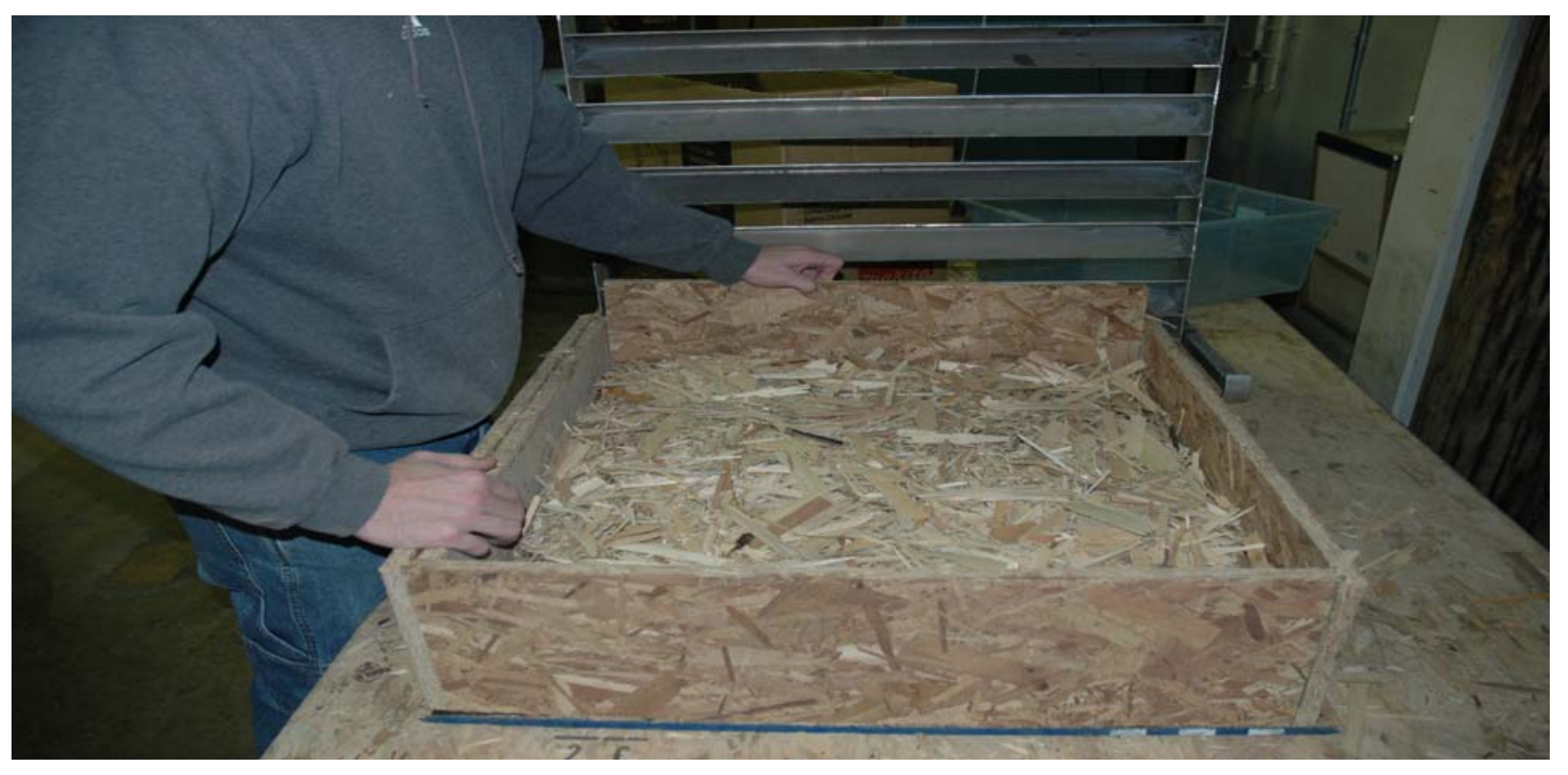

Figure 13. Removal of spacer

Removing this layer from one side of the form allowed a small amount of clearance to aid in reducing disturbance of the mat shape as the form was lifted vertically off of the formed mat. Once the form was removed, the mat was carried to the press on the tray and inserted as shown in figure 14. 


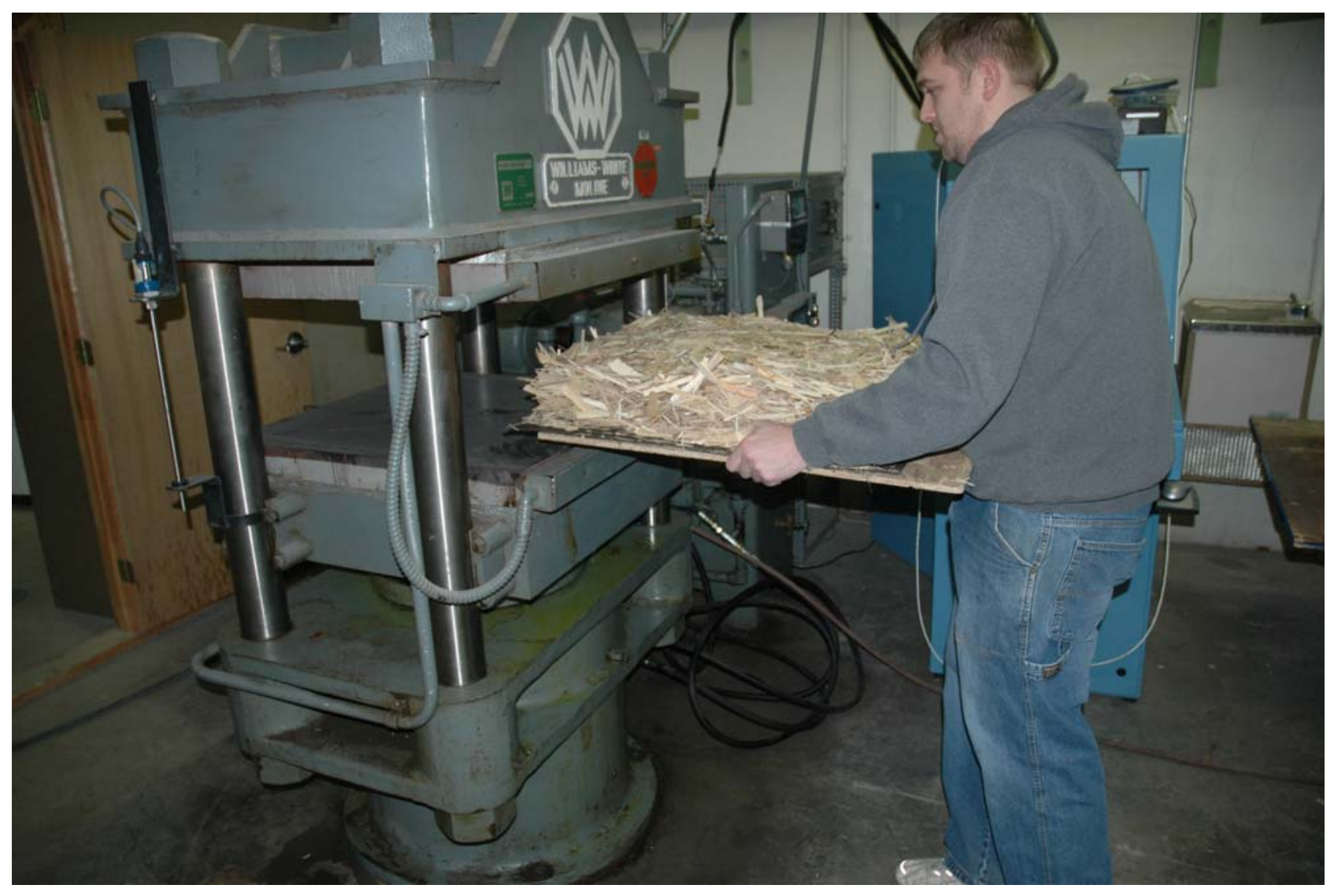

Figure 14. Placement of mat into press

With the mat in position, the press probe was inserted approximately 12 inches into the edge of the mat, centered both vertically and horizontally. The probe monitored press pressure, mat gas pressure, and internal mat temperature. At this time, the press close button was pushed to begin the press cycle that was programmed using Pressman software. The press control panel can be seen in Figure 15. 


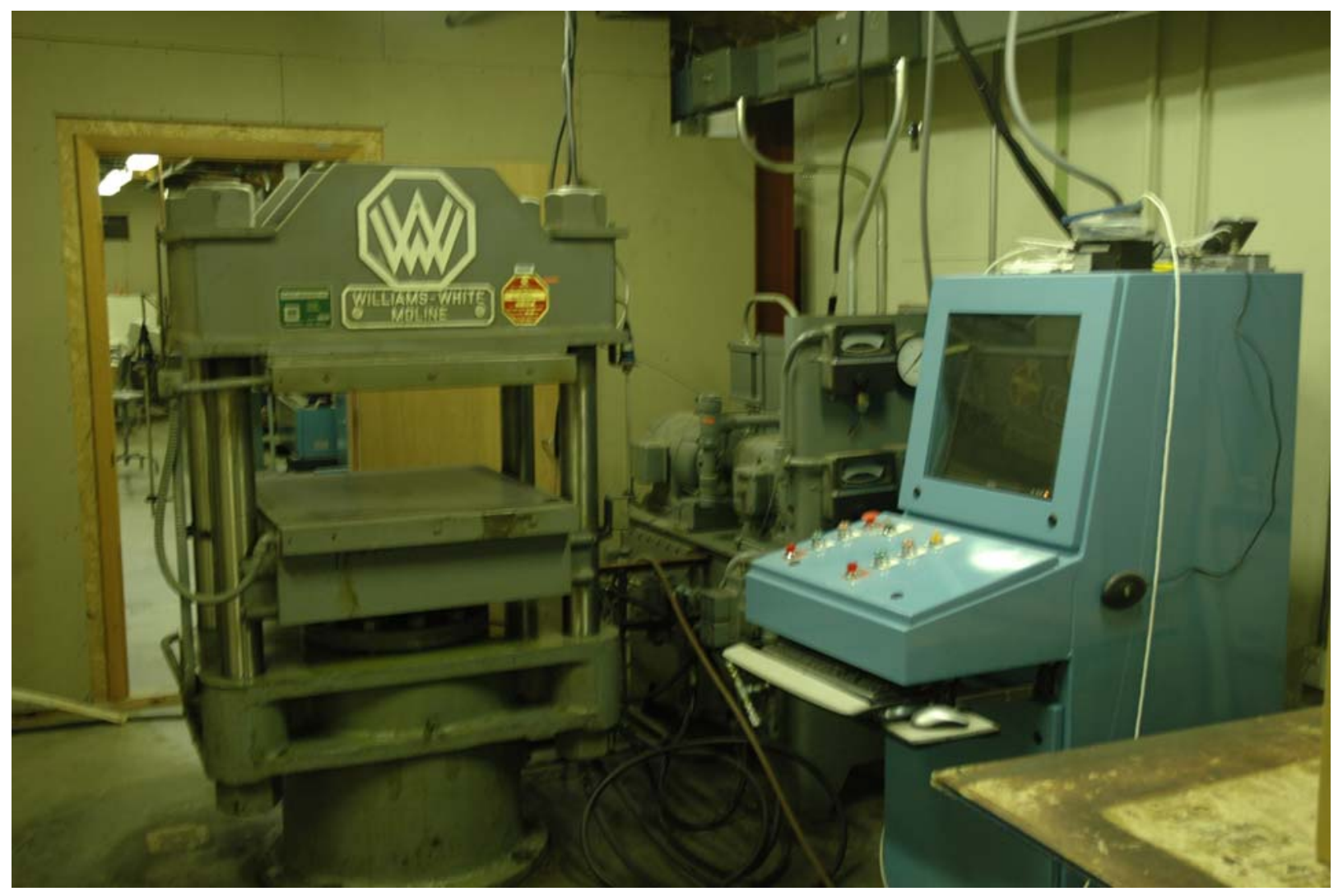

Figure 15. Press (left), Press control panel (right)

The press program began by closing at a rapid rate until it reached 0.690 ". The press then held at 0.690 " for 5 seconds, .670 " for 10 seconds, and finally completely closed at 0.650 " for 230 seconds. The program then began degasification by opening 0.003 " for 20 seconds, 0.003 " more for 15 seconds, and finally 0.003 " more for 15 seconds. These degasification cycles allowed internal mat gas pressure to escape gradually without causing the panel to "blow". Blow is a term used in industry to describe the uncontrolled escape of hot gasses created inside the mat during pressing. Blows occur when the press releases holding pressure and internal pressures due to the hot gasses exceed the internal bond strength of the mat. After the last degasification cycle, the 
press began opening at full speed. Thermal protective gloves were worn to pull the press probe out of the panel and remove the panel and caul screen from the press. The hot panels were placed on a concrete floor to cool. This pressing process proved satisfactory and was used for the production of 30 final test panels.

\section{Testing Trial Panels}

In the initial production of trial panels, several variables in the panel production process were explored before settling on the process used for the final 30 test panels. Since the resin addition rate used for high value OSB flooring panels in the OSB industry is purported to be $6 \%, 6 \%$ was the rate used when making the first trial panels. Spraying the solution of chlorine bleach and water on the strands showed that resin coverage was significantly less than the target of $50 \%$. Panels were tested for internal bond (IB) strength, otherwise known as tension perpendicular to the grain. IB test specimens were cut approximately 2"x2" in accordance with ASTM 1037D. After cutting to size, top and bottom surfaces were briefly smoothed on a belt sander to aid with adhesion of hot melt glue and aluminum test machine brackets. The goal was to remove as little wood as possible while creating a flat surface. Aluminum brackets were placed on hot plates and a small amount of hot melt glue was placed on each bracket surface. Once glue was completely liquefied, one side of the specimen was applied to the glue and bracket. While remaining on the hot plate, pressure and slight rotation was applied to the specimen on top of the bracket to aid in spreading glue evenly between the bracket and specimen. Bracket and specimen were then 
transported to a cool water bath using a pair of tongs to grasp only the bracket. Water in the bath was approximately $1 / 4$ " in depth and only contacted the aluminum bracket. Cooling and curing occurred within minutes. With one bracket attached, the process was repeated by gluing another bracket to the remaining surface of the specimen. See figure 16.

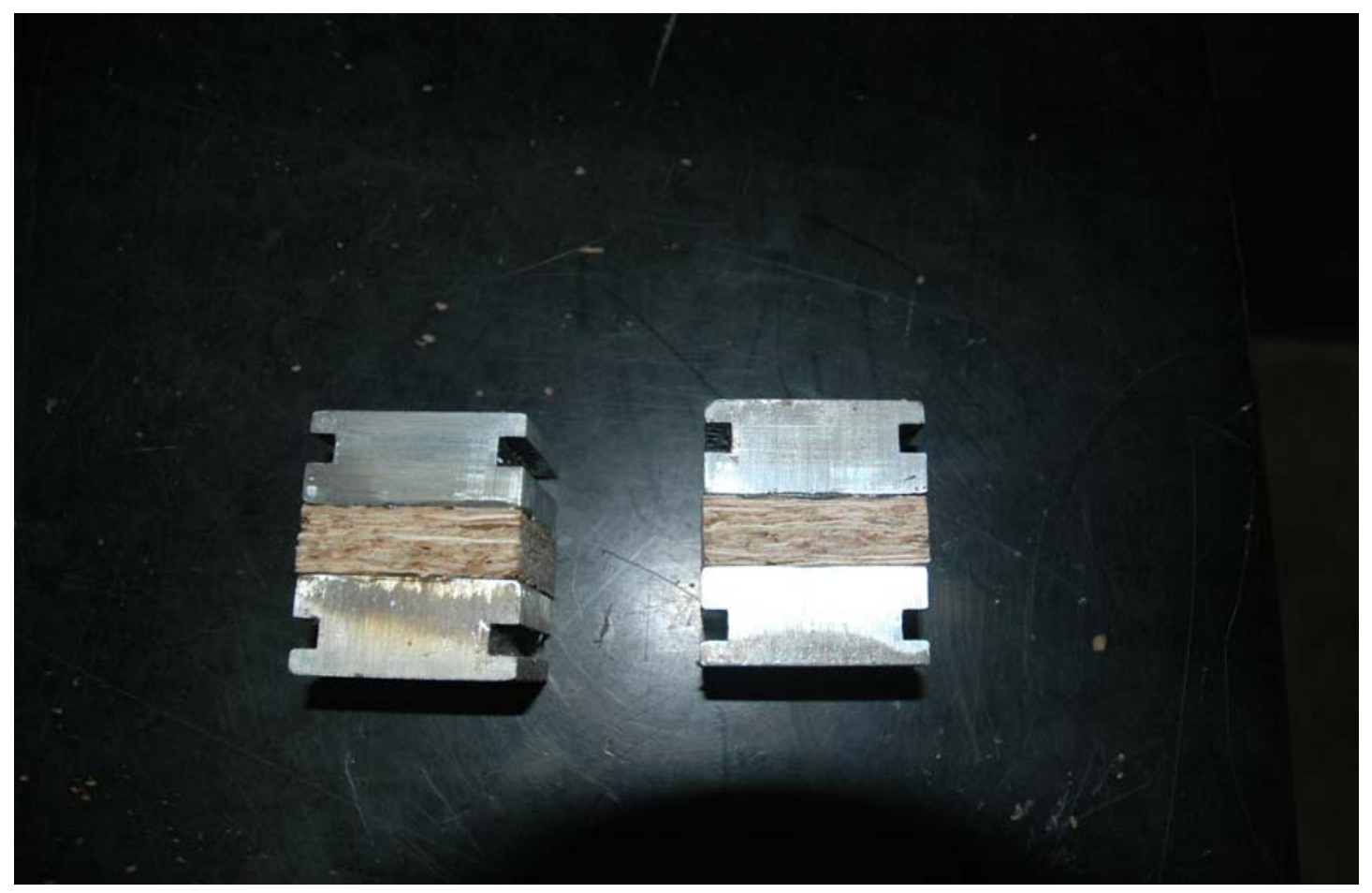

Figure 16. Internal bond testing specimens with brackets attached

With brackets attached and glue cured, specimens were ready for testing. Testing began by programming the MTS test machine to move at a rate of .04 in/min in accordance with ASTM D 1037 and display applied load in Ibs. Strength was drastically insufficient and some specimens nearly fell apart under their own weight or could be pulled apart by hand. Target panel thickness was 0.719 " (23/32"), but to account for spring back that occurs when press pressure is released, panels were pressed at 0.700 in. Due to a lack of bonding or 
excessive spring back, post-pressing panel thicknesses ranged from 0.800 "$0.865 "$ which was unsatisfactory.

Changes in resin addition and pressing were made to address these thickness and bonding issues. Since the blending setup used in this research was not as efficient or advanced as those used in industry, a resin addition rate of $8 \%$ was applied. Spray testing with bleach showed improved resin coverage over the $6 \%$ addition rate but still lacking the $50 \%$ goal. To combat thickness issues, the press program was also altered to press at 0.680 " instead of 0.700 " which led to thick panels. Panels produced after making these changes had an average thickness of 0.765 " and were also very weak in IB strength.

Resin coverage improved by increasing the addition rate to $8 \%$; a $10 \%$ addition rate was attempted next. Blended strands were sprayed with the bleach and water solution and revealed satisfactory coverage. Resin coverage looked promising, then panel thickness issues were addressed. From the first trial to the second, the press close settings were changed from 0.700 " to 0.680 " but resulted in changing the pressed panel thickness from approximately 0.825 " to 0.780 ". Therefore, it seemed as though the decrease in panel thickness was approximately double the change in the press setting. Panel thickness needed to shrink 0.061 ". Based on the previous results, it was decided to reduce the press setting by 0.030 " for the third trial. The press was programmed to close at 0.650 " and panel production resumed. 
Upon examining the new trial panels, measured thickness averaged very close to the target of $0.719 "$. Cut edges of the IB specimens also revealed visible improvement in panel edge density and bonding. Specimens were once again glued to the aluminum brackets and tested. As the visual observations and measurements suggested, IB values for the third trial panels were much improved and satisfactory. A minimum value of 25 psi. is the standard benchmark for flooring IB strength in industry. The third trial panels averaged well above 30 psi.

Using a $10 \%$ addition rate was somewhat of a concern considering industry uses $6 \%$. But for the purpose of this research, keeping the resin addition rate constant among the panels would allow a fair comparison between research panels made with oak and research panels made with standard strands. Comparing research panels to industrial board would not be as relevant considering the differences in production equipment.

\section{Production of research panels}

Production of satisfactory trial panels gave the confidence necessary to begin using the limited supply of oak strands in production of the 30 research panels. Equipment malfunction is always a possibility, therefore the decision was made to randomize the order in which panels were made rather than make one type of panel consecutively. For instance, if there was an unknown problem, it would be less detrimental to the study if its effect were to be spread out between panel 
types as opposed to affecting all of one panel type. For this reason, only two panels of each type were made consecutively.

Production of research panels was performed in the same manner as described for the trial panels, produced previously. Production began by blending two batches of each type of furnish: standard surface, standard core, oak surface, and oak core. A batch consisted of $6.630 \mathrm{lb}$. (3000g.) of furnish. A $10 \%$ resin addition rate was applied to all furnish. Since the intent of this research was to compare the performance of panels containing oak to standard panels, production started with making 2 control panels containing standard mixed hardwood furnish from Weyerhauser OSB mill in Heaters, WV. Once again, the standard furnish contained a very small percentage, if any, oak strands. $3.315 \mathrm{lb}$. (1500g.) of resonated surface strands were used in each of the two surface layers, and $6.630 \mathrm{lb}$. (3000g.) of resonated core strands were used in the core layer. All research panels were pressed to 0.650 " using the same press program as described for the trial panels. Blending of furnish continued throughout the process on an as needed basis.

Once the two control panels were pressed and cooled, production of two $25 \%$ oak panels began. $25 \%$ oak panels were made in the same manner as the controls except for the difference in the amount of each type of strands contained in each layer. Both surface layers in the $25 \%$ oak panels contained $.829 \mathrm{lb}$. (375g.) of wet oak surface strands and $2.486 \mathrm{lb} .(1125 \mathrm{~g}$.) of wet standard surface strands. The core layer in the $25 \%$ oak panels consisted of $1.658 \mathrm{lb}$. (750g.) of 
wet oak core strands and $4.725 \mathrm{lb}$. (2,250g.) of wet standard core strands. Once weighed, the oak and standard strands were combined and mixed in a large plastic container before forming each layer of the mat. For instance, before forming the first surface layer, $.829 \mathrm{lb}$. (375g.) of oak surface furnish was mixed with $2.486 \mathrm{lb}$. (1125g.) of standard surface furnish. Two $25 \%$ oak panels were formed and pressed as before. The panels were removed from the press and allowed to cool.

Two $50 \%$ oak panels were produced. Both surface layers in the $50 \%$ oak panels contained $1.658 \mathrm{lb}$. (750g.) of wet standard surface furnish and $1.658 \mathrm{lb} .(750 \mathrm{~g}$. of wet oak surface furnish. The core layer in the $50 \%$ oak panels contained $3.315 \mathrm{lb} .(1500 \mathrm{~g}$.) of wet standard core furnish and $3.315 \mathrm{lb}$. (1500g.) of wet standard core furnish. The two strand types for each layer were mixed before forming, as described previously. Two $75 \%$ oak panels were produced next. Both surface layers in the $75 \%$ oak panels contained $2.486 \mathrm{lb}$ (1125g.) of wet oak surface furnish and $.829 \mathrm{lb}$. (375g.) of wet standard surface furnish. The core layer in the $75 \%$ oak panels contained $4.725 \mathrm{lb} .(2,250 \mathrm{~g}$.) of wet oak core furnish and $1.658 \mathrm{lb}$. (750g.) of wet standard core furnish. The furnish composing each layer was mixed as before, panels were formed, pressed and allowed to cool. Last, two $100 \%$ oak panels were produced. Both surface layers in the $100 \%$ oak panels contained $3.315 \mathrm{lb}$ ( $(1500 \mathrm{~g}$.) of wet oak surface furnish. The core layer in the $100 \%$ oak panels contained $6.630 \mathrm{lb}$. (3000g.) of wet oak core furnish. As with the control panels no mixing was necessary before forming 
the $100 \%$ oak panels. Panels were pressed and allowed to cool, which completed the first day of panel production.

Two more days of production nearly identical to this were performed which completed the 30 research panels. All variables and methods within our control were kept constant throughout the three days of production. Furnish moisture content, resin addition rate, blending setup, scale used for weights, forming method, press temperature and cycle, etc. were all kept constant throughout the production of the 30 research panels.

\section{Preparing Specimens for Testing}

Upon completion of the 30 panels, sample size preparation for test specimens was devised. 4 flexure specimens, 5 IB specimens, and 2 nail withdrawal specimens were cut out of each panel, all according to ASTM D 1037 specifications.

The flexure specimens were of approximate dimensions 3"W x 19.25"L. The length of these specimens was parallel to the long direction of surface strand orientation. Specimens were cut in this manner in order to simulate the strand orientation of a flooring panel that is spanning joists. Specimen length was determined using the following equation. (ASTM D 1037) 


\section{$L=2$ in. $+(24 *$ Nominal $T)$}

Where:

$L=$ specimen length

$\mathrm{T}=$ specimen thickness

IB specimens were cut 2" x 2" and nail withdrawal specimens were 3.5 " x 6.0". Flexure specimens were labeled with the treatment first, panel \# second, and specimen \# third. Prior to testing, measurements were taken on every specimen.

Flexure specimens were measured for width and thickness at each end and middle using a digital caliper accurate to .001". The three length and width measurements were recorded and averaged to obtain the most accurate measurement of each. From these measurements, section modulus and moment of inertia were calculated for each flexure specimen.

Section modulus was calculated using this equation:

$$
S_{x}=W_{a v g} * T_{a v g}{ }^{2} / 6
$$

Where:

Sx $=$ Section modulus $\left(\mathrm{in}^{3}\right)$

W = specimen width (in)

$\mathrm{T}=$ specimen thickness (in) 
Moment of inertia was calculated using the following equation:

$$
\mathrm{I}_{\mathrm{x}}=\mathrm{W}_{\mathrm{avg}}{ }^{*} \mathrm{~T}_{\mathrm{avg}}{ }^{3} / 12
$$

Where:

$\mathrm{Ix}=$ Moment of inertia $\left(\mathrm{in}^{4}\right)$

$\mathrm{W}=$ specimen width (in)

$\mathrm{T}=$ specimen thickness $($ in)

Flexure specimen length was measured once per specimen using a steel tape measure accurate to $1 / 16$ " and recorded. Specimens were also weighed on a scale accurate to $0.1 \mathrm{~g}$. Using weights and dimension measurements, densities were calculated for each flexure specimen.

The formula used to calculate density was:

$$
\rho=(L \times W \times T) / \text { Mass }
$$

Where:

$\rho=$ density

$L=$ length of specimen (in)

W = width of specimen (in)

$\mathrm{T}=$ thickness of specimen (in) 
IB specimens were labeled in the same manner as flexure specimens. Exact length and width measurements were taken using a digital caliper accurate to 0.001". Measurements were recorded for each IB specimen.

Nail withdrawal specimens were labeled treatment first, and panel number second. Two nail withdrawal specimens were cut for each panel and both specimens were labeled alike. Exact thickness was measured using a digital caliper accurate to $0.001 "$ and measurements were recorded. To complete preparation of the nail withdrawal specimens, nails of 0.113 in. in diameter (8p) were driven at right angles to the surface until nail tip exited bottom surface.

\section{Static testing}

Once all exact measurements were recorded and specimens were prepared, flexure specimens were tested in static bending for MOR and apparent MOE. Testing was performed using an MTS universal testing machine with a 2,000 lb. load cell (as shown in figure 17.) The test machine was checked for calibration prior to testing. The testing setup was 3-point bending with a span of 17.25 in. and a load application block that was centered between the supports. The radii of the load application and support blocks were in accordance with ASTM D 1037. Load was applied to the specimen by the load application block at a constant rate of $0.35 \mathrm{in} . / \mathrm{min}$. 


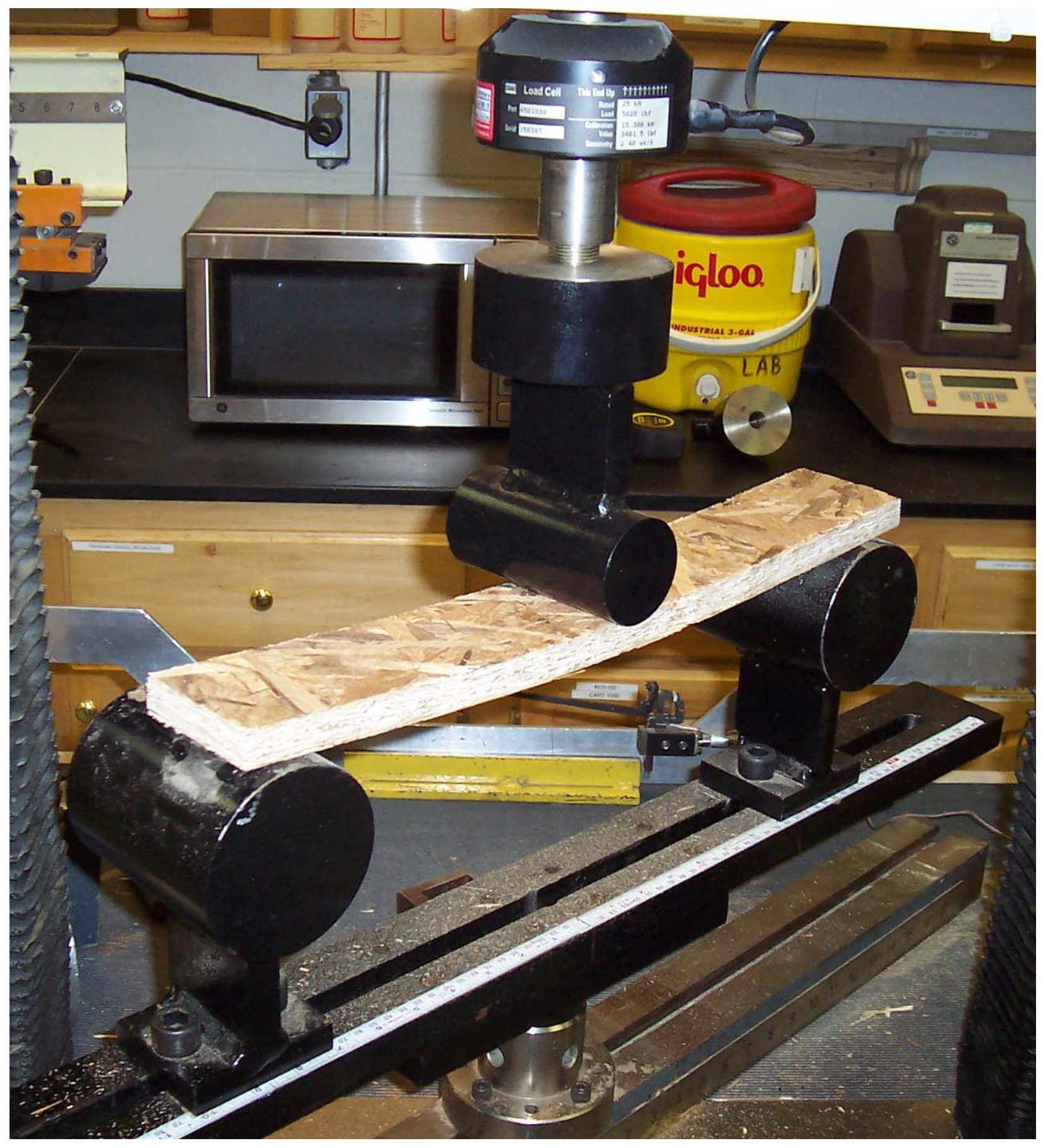

Figure 17. Static Bending Test Setup 
Testing speed was determined using this equation:

\section{$N=z^{2} / 6 d$}

Where:

$\mathrm{N}=$ rate of motion of moving head, in./min

$z=$ unit rate of fiber strain, in./in. of outer fiber length per minute $(0,005)$

$L=$ span, in.

$\mathrm{d}=$ depth (thickness) of specimen, in.

Deflection was measured using the displacement of the crosshead from the instant of first applied load. Load and deflection data were recorded by a computer data acquisition system every second after the first applied load until failure.

After testing was completed, load and deflection data was plotted as a simple scatter plot using the deflection data as $X$ values and load data as $Y$ values. Linear regression was performed on the linear elastic region of the data and the deflection was corrected so to pass through the origin of the graph. After correction, the load and deflection data were used to calculate MOR, apparent MOE, and maximum moment. 
For three-point load condition, maximum moment was calculated using the following equation:

\section{$M \max =\left(F \max { }^{*} L\right) / 4$}

Where:

Mmax = maximum moment (in-lbs)

Fmax $=$ maximum breaking force (lbs)

$L=$ testing span (in)

Apparent MOE was calculated using the following equation:

\section{$\mathrm{MOE}_{\mathrm{A}}=\mathrm{FL}^{3} / 48 \mathrm{I}_{\mathrm{x}} \Delta$}

Where:

$\mathrm{MOE}_{\mathrm{A}}=$ apparent modulus of elasticity (psi)

$\mathrm{F}=$ load (lbs)

$\mathrm{L}=$ testing span (in)

$\mathrm{I}_{\mathrm{x}}=$ moment of inertia $\left(\mathrm{in}^{4}\right)$

MOR was calculated using the following formula:

$$
\text { MOR }=M_{\max } / S_{x}
$$

Where:

MOR $=$ modulus of rupture $(p s i)$

$\mathrm{M}_{\max }=$ maximum momoment (in-lbs)

Sx $=$ section modulus $\left(\mathrm{in}^{3}\right)$ 


\section{Nail Withdrawal Testing}

After completion of the static bending testing, nail withdrawal testing began, using ASTM protocol. An MTS universal testing machine, with a $2000 \mathrm{lb}$. load cell, was used for nail withdrawal testing. The testing setup consisted of an upper and lower bracket. The upper bracket, attached to the crosshead, supported a 3/16" square steel plate on opposite sides. A groove was cut from the outside of the plate leading to a recessed area in the center where the nail head could rest. The bottom bracket was designed to hold the specimen in place while allowing the nail to pass upwards through a slot leading to the top bracket. The load was applied to the specimen throughout the test by a uniform motion of the crosshead at a rate or $0.06 \mathrm{in} . / \mathrm{min}$. The maximum load required to withdraw the nail was recorded for each specimen. Since two specimens were tested for each panel, the two maximum load results were averaged to obtain final values for each panel.

\section{Internal Bond Testing}

Internal bond testing was performed to determine the cohesion of the OSB perpendicular to the surface of the board. Length and width measurements were taken for each specimen using a digital caliper accurate to $0.001 \mathrm{in}$. These measurements were multiplied together to determine the bonding area of each specimen. Once again specimens were hot melt glued to aluminum brackets as described earlier during the testing of the trial panels. After gluing all specimens to brackets the MTS universal test machine was programmed to test at a constant rate of $0.08 \mathrm{in.} / \mathrm{min}$. in accordance with ASTM D 1037. Specimens were 
placed in the testing jig and tested to failure. Maximum applied load was recorded for each specimen and divided by the bonding area to obtain a strength value in pounds per square inch. Testing setup can be seen in figure 18.

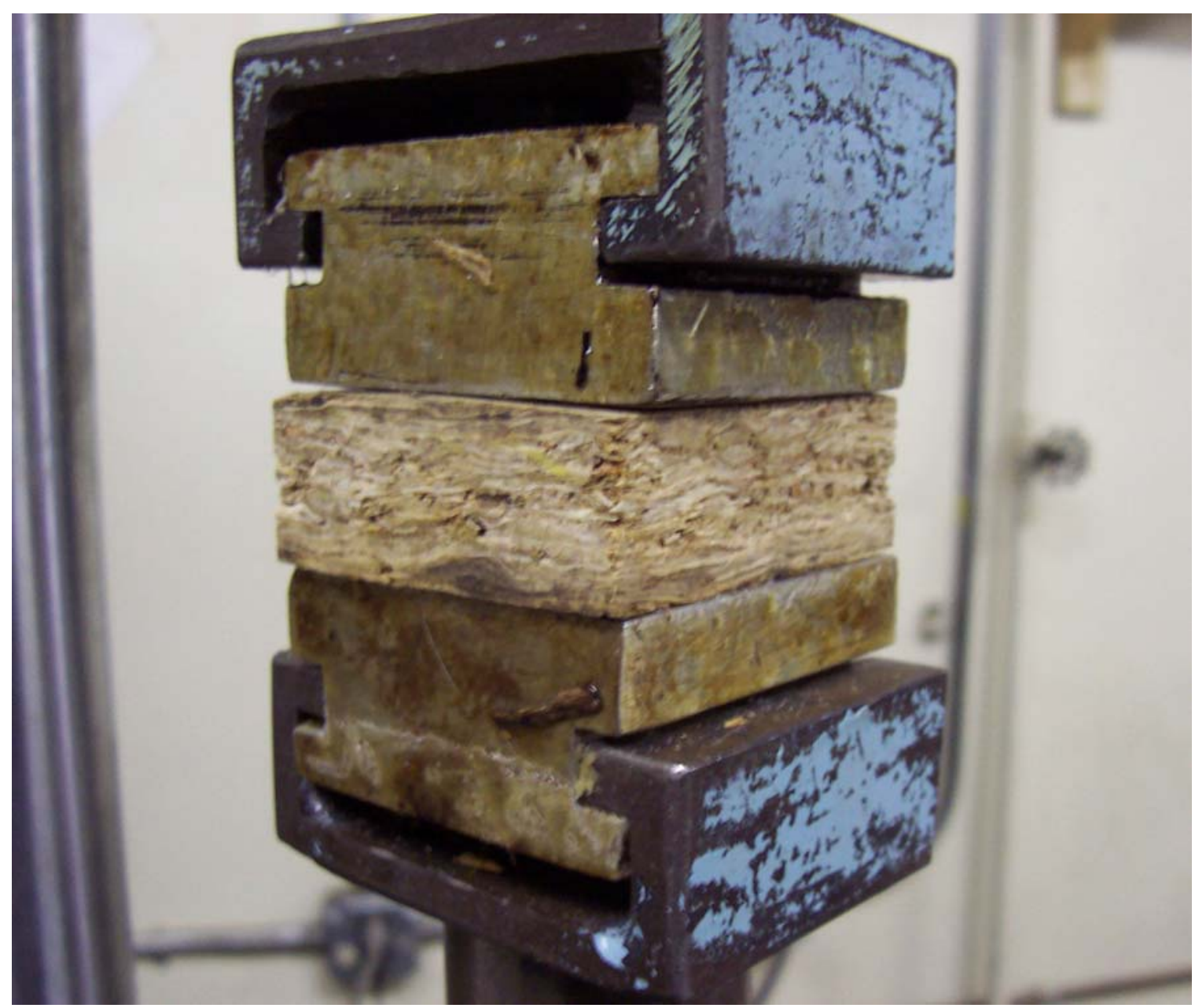

Figure 18. Internal bond testing setup 


\section{Statistical Methods}

The maximum moment (MMAX), maximum force (FMAX), modulus of elasticity (MOE), and modulus of rupture (MOR) were investigated for differences among levels of oak incorporation. Analysis of variance (ANOVA) was used to determine if any differences in MMAX, FMAX, MOE, and MOR existed among treatments. The ANOVA model can be stated as follows:

$$
y_{i}=\mu+\alpha_{i}+\delta_{i j}+\beta_{i j}+\varepsilon_{i j k}
$$

Where:

$y_{i}=$ variable of interest (MMAX, FMAX, MOE, MOR)

$\mu=$ overall mean

$\alpha_{i}=$ main effect of treatment (Control, $25 \%$ oak, $50 \%$ oak, $75 \%$ oak, $100 \%$ oak)

$\delta_{i j}=$ random effect of panels within treatment

$\beta_{i j}=$ panel density as a covariate

$\varepsilon_{i j k}=$ random effect that represents all uncontrolled variability (error term)

Density was used as a covariate to adjust MMAX, FMAX, MOR, and MOE. To include these adjustments, the least squares means approach was used for multiple comparisons. All effects were considered significant at $\alpha \leq 0.05$. 


\section{Results}

The descriptive statistics resulting from the observed optimum stranding variables of the first study are shown in Table 1. "Length" and "width" variables are weighted average results. "Thickness" is average strand thickness from the $1 \frac{1}{4}$ inch classification, not a weighted average. Both studies reveal very similar results. Average strand length from the first trial of West Virginia logs was 3.9 inches, while the second run of German white oak was 3.4 inches. During the stranding setup, a "scoring tip" was inserted in the knife assembly. The purpose of the scoring tip was to cut the strands into the desired length. Targeted strand length may range from 3 to 5 inches. During this study the scoring tips were setup to target a 4 inch strand length. From the results of the two tests we found that the oak species produced satisfactory strand length.

\begin{tabular}{|c|c|c|c|c|c|c|}
\hline Variable & $\mathbf{n}$ & Mean & St.Dev. & Minimum & Median & Maximum \\
\hline Length & 6 & 3.899 & 0.026 & 3.859 & 3.898 & 3.939 \\
\hline Width & 6 & 0.744 & 0.092 & 0.623 & 0.735 & 0.896 \\
\hline Thickness & 300 & 0.029 & 0.007 & 0.013 & 0.029 & 0.061 \\
\hline$\%<3 / 16 "$ & 6 & 10.030 & 1.810 & 7.370 & 10.220 & 12.010 \\
\hline $\begin{array}{l}\% 1 " \text { + } \\
\text { Trial } 2\end{array}$ & 6 & 66.940 & 5.040 & 59.820 & 67.680 & 72.400 \\
\hline Length & 3 & 3.407 & 0.085 & 3.310 & 3.440 & 3.470 \\
\hline Width & 3 & 0.727 & 0.095 & 0.630 & 0.730 & 0.820 \\
\hline Thickness & 150 & 0.030 & 0.007 & 0.010 & 0.062 & 0.030 \\
\hline$\%<3 / 16 "$ & 3 & 4.767 & 0.643 & 4.300 & 4.500 & 5.500 \\
\hline \% 1" + & 3 & 70.333 & 1.528 & 69.000 & 70.000 & 72.000 \\
\hline
\end{tabular}


We also found that the studies provided a weighed average strand width of 0.74 and 0.73 inches for the first and second studies respectively. The knife setup used targeted a strand width of 1 inch. Figure 19 shows typical strand geometry from previous attempts of stranding oak, while Figure 120 shows the quality of strands obtained from our trials. A graphical representation of the distribution of the strand geometry for the first and second trial may be seen in Figure 21. The classification data is shown as $<3 / 16$ " ( fines) and 1"+ (strand material). 


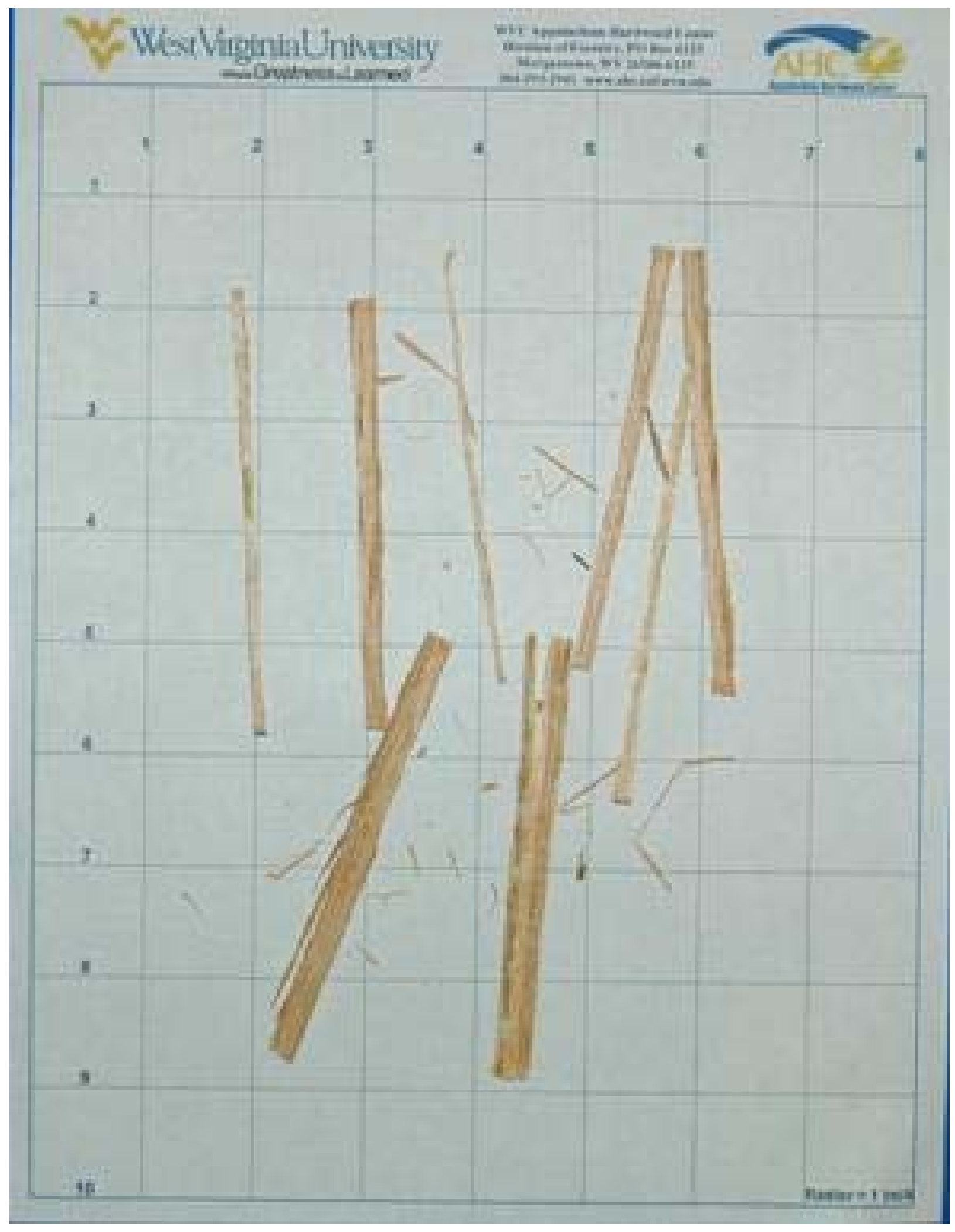

Figure 19. Typical Oak Strands ( 1" grid ) 


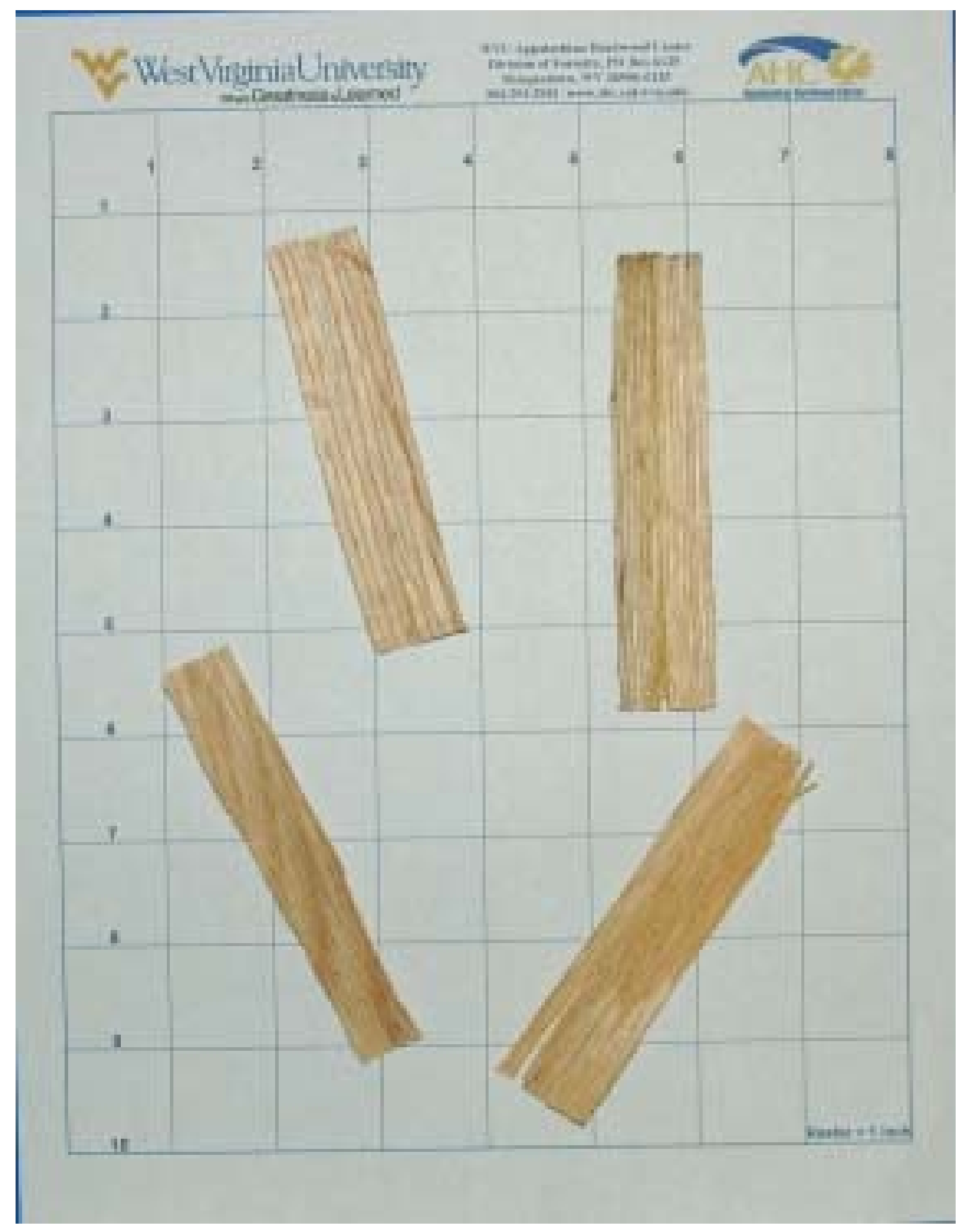

Figure 20. Oak strands created at Pallman Co. (1" grid ) 


\section{Distribution of Strand Geometry}

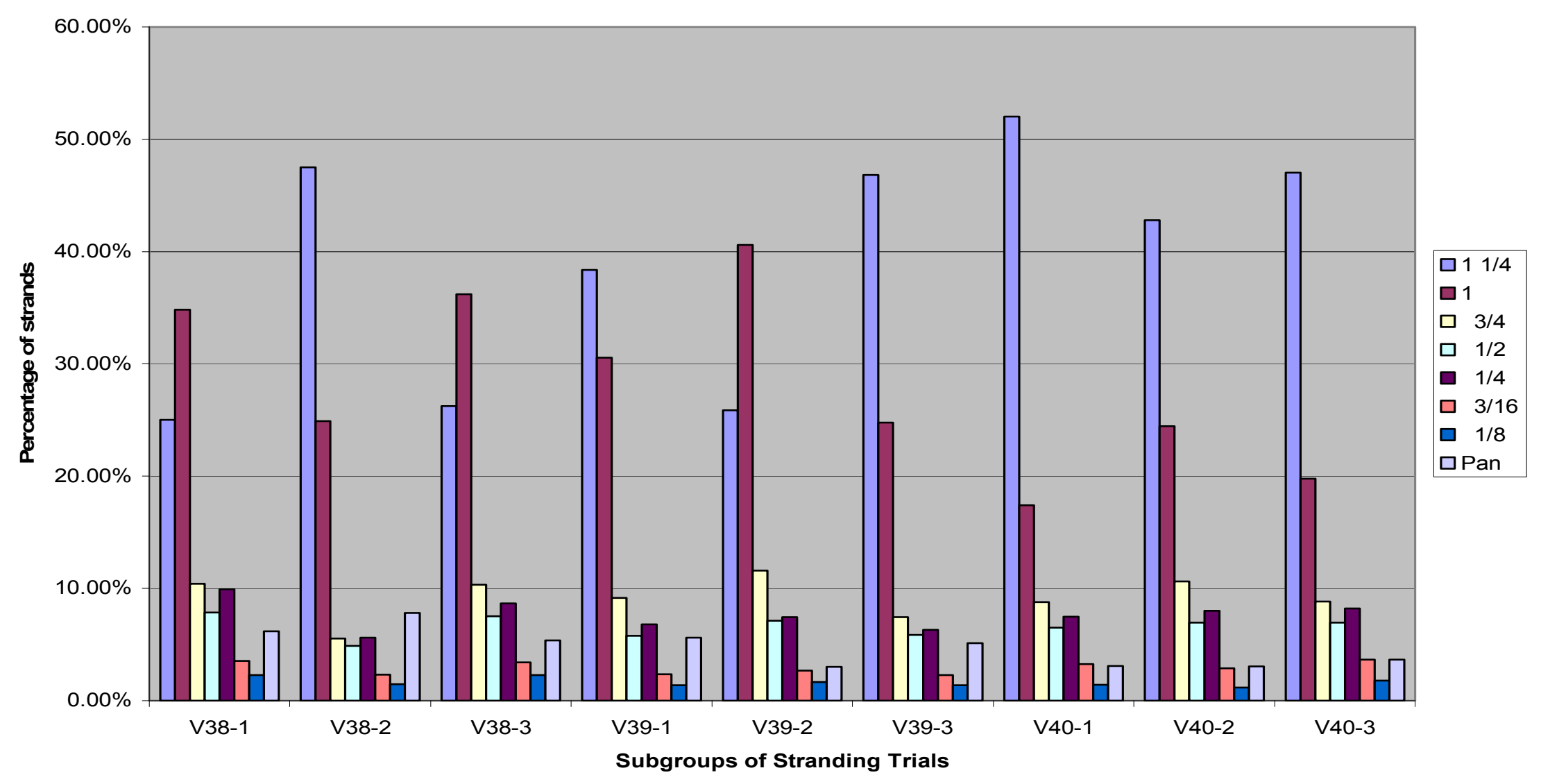

Figure21. Distribution of Oak Strand Geometry 
Most impressive about the results obtained from this trial was the percentages of fines content $(<3 / 16$ " BMM screen classifier) and strands larger than 1 inch (BMM screen classifier). From Table 1, we found that the largest concentration of strands was in the 1 inch and larger categories, consisting of $67 \%$ and $70 \%$ from the first and second study respectively. Between the two trials we did notice a slight difference in fines content. The first trial yielded a fines content of $10 \%$ while the second provided a very impressive $4.7 \%$. Mixed hardwood furnish usually yields between 15 and 25 percent fines. Fines are usually considered an undesirable byproduct of the stranding process.

Statistical analysis of the flexure test results revealed significant differences $(P<$ 0.05 ) in panels containing oak and control panels in all but two categories. No significant difference in $\mathrm{F}_{\max }$ was observed between $25 \%$ oak panels and control panels $(P=0.2477)$. Also, no statistically significant difference was observed in MOE between $25 \%$ oak panels and control panels $(P=0.7406)$. Significant differences from ANOVA results are shown in Table 2. Descriptive statistics of IB and nail withdrawal testing revealed a direct relationship between oak content and strength as shown in Table 3. As oak content increased IB and nail withdrawal strength decreased. Furthermore, Figure 22 shows a direct relationship between MOE and density with the relationship applying less to panels with $75 \%$ or more oak, presumably due to compaction ratio insufficiencies. 
Table 2. Significant Differences From ANOVA Results

$F \max$

Control

25

50

75

100

\begin{tabular}{|l|l|l|l|l}
\multicolumn{1}{c}{ control } & $\mathbf{2 5}$ & $\mathbf{5 0}$ & $\mathbf{7 5}$ & $\mathbf{1 0 0}$ \\
\hline & no & yes & yes & yes \\
\hline no & & yes & yes & yes \\
\hline yes & yes & & yes & yes \\
\hline yes & yes & yes & & yes \\
\hline yes & yes & yes & yes &
\end{tabular}

\section{Max}

Control

25

50

75

100

\begin{tabular}{|l|l|l|l|l}
\multicolumn{1}{c}{$\mathbf{2 5}$} & $\mathbf{5 0}$ & $\mathbf{7 5}$ & $\mathbf{1 0 0}$ \\
\hline & yes & yes & yes & yes \\
\hline yes & & yes & yes & yes \\
\hline yes & yes & & yes & yes \\
\hline yes & yes & yes & & yes \\
\hline yes & yes & yes & yes &
\end{tabular}

MOE

Control

25

50

75

100

\begin{tabular}{|l|l|l|l|l}
\multicolumn{1}{c}{ control } & \multicolumn{1}{c}{$\mathbf{5 0}$} & $\mathbf{7 5}$ & $\mathbf{1 0 0}$ \\
\hline & no & yes & yes & yes \\
\hline no & & yes & yes & yes \\
\hline yes & yes & & yes & yes \\
\hline yes & yes & yes & & yes \\
\hline yes & yes & yes & yes &
\end{tabular}

MOR

Control

25

50

75

100

\begin{tabular}{|l|l|l|l|l}
\multicolumn{1}{c}{ control } & \multicolumn{1}{l}{$\mathbf{5 0}$} & $\mathbf{7 5}$ & $\mathbf{1 0 0}$ \\
\hline & yes & yes & yes & yes \\
\hline yes & & yes & yes & yes \\
\hline yes & yes & & yes & yes \\
\hline yes & yes & yes & & yes \\
\hline yes & yes & yes & yes &
\end{tabular}




\section{Panel Density VS MOE}

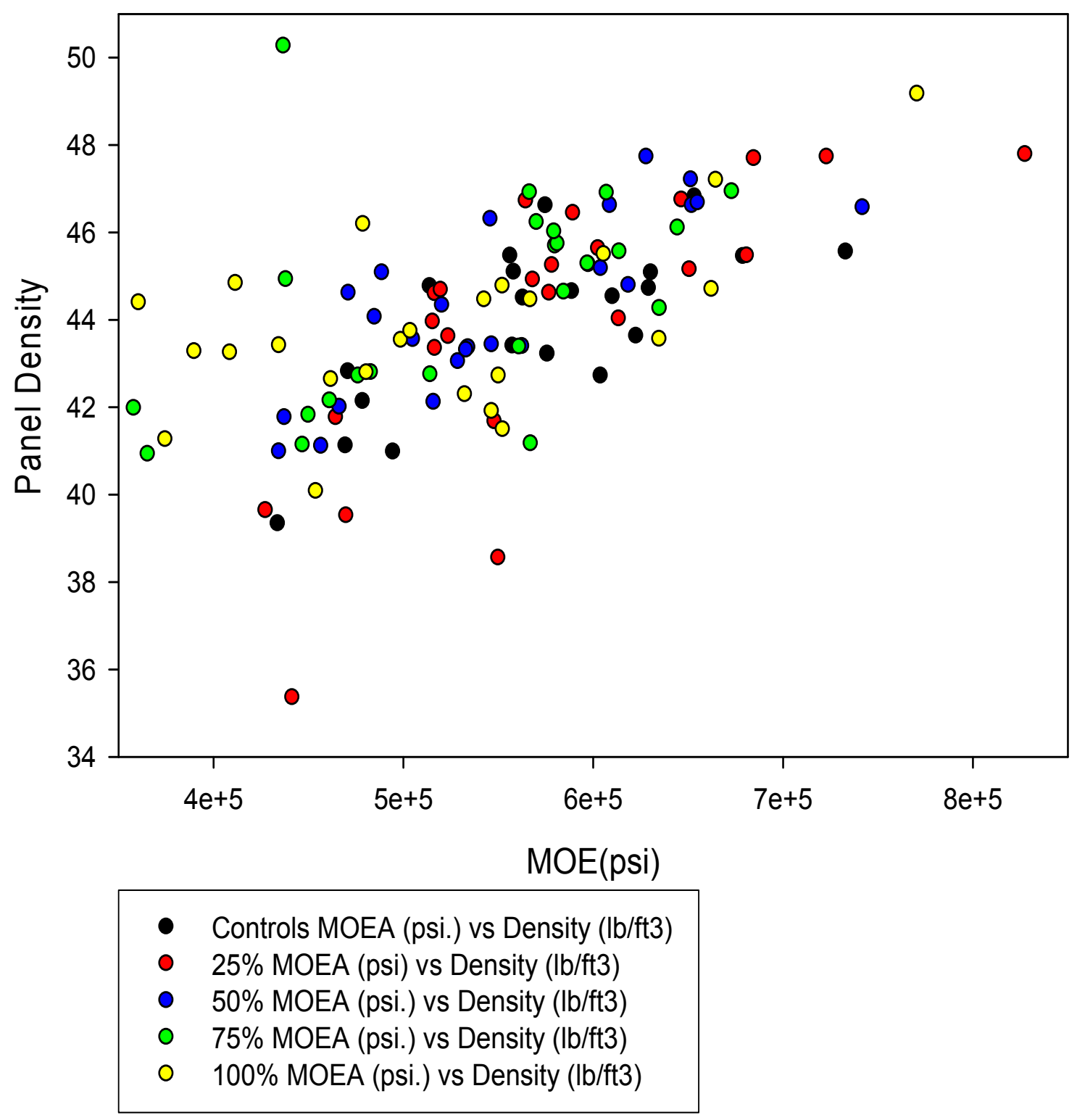

Figure 22. Scatter plot of panel density vs. MOE 
Table 3. Summary statistics of the overall test results.

\begin{tabular}{|c|c|c|c|c|c|c|c|c|}
\hline & & Mmax (in Ib) & F max (Ib) & MOR (psi) & $\mathrm{MOE}_{\mathrm{A}}(\mathrm{psi})$ & $\begin{array}{l}\text { Nail } \\
\text { Withdrawal } \\
\text { Force (lb) }\end{array}$ & IB Force (psi) & Density $\left(\mathrm{Ib} / \mathrm{ft}^{3}\right)$ \\
\hline Control & $\begin{array}{l}\text { Mean } \\
\text { Std. Dev. } \\
\text { Min } \\
\text { Max }\end{array}$ & $\begin{array}{l}1398.73 \\
576.03 \\
842.19 \\
3066.04\end{array}$ & $\begin{array}{l}248.54 \\
39.62 \\
175.00 \\
320.00\end{array}$ & $\begin{array}{l}4728.98 \\
1828.51 \\
2656.37 \\
10102.75\end{array}$ & $\begin{array}{l}571504.95 \\
71251.96 \\
434243.34 \\
733494.64\end{array}$ & $\begin{array}{l}121.78 \\
42.51 \\
63.8 \\
202.2\end{array}$ & $\begin{array}{l}31.69 \\
10.74 \\
8.61 \\
55.65\end{array}$ & $\begin{array}{l}43.98 \\
1.81 \\
39.32 \\
46.80\end{array}$ \\
\hline $25 \%$ Oak & $\begin{array}{l}\text { Mean } \\
\text { Std. Dev. } \\
\text { Min } \\
\text { Max }\end{array}$ & $\begin{array}{l}1139.56 \\
266.80 \\
683.38 \\
1746.94\end{array}$ & $\begin{array}{l}236.79 \\
55.44 \\
142.00 \\
363.00\end{array}$ & $\begin{array}{l}3952.95 \\
954.79 \\
2385.68 \\
6214.49\end{array}$ & $\begin{array}{l}576258.76 \\
93962.02 \\
427822.29 \\
827929.03\end{array}$ & $\begin{array}{l}119.36 \\
50.70 \\
44.3 \\
232.8\end{array}$ & $\begin{array}{l}19.68 \\
10.05 \\
5.40 \\
49.17\end{array}$ & $\begin{array}{l}43.97 \\
3.15 \\
35.34 \\
47.77\end{array}$ \\
\hline $50 \%$ Oak & $\begin{array}{l}\text { Mean } \\
\text { Std. Dev. } \\
\text { Min } \\
\text { Max }\end{array}$ & $\begin{array}{l}1069.78 \\
275.66 \\
712.25 \\
1578.50\end{array}$ & $\begin{array}{l}222.29 \\
57.28 \\
148.00 \\
328.00\end{array}$ & $\begin{array}{l}3670.50 \\
997.58 \\
2383.59 \\
5516.28\end{array}$ & $\begin{array}{l}550110.14 \\
79918.98 \\
434986.40 \\
742323.49\end{array}$ & $\begin{array}{l}108.49 \\
66.67 \\
43.7 \\
281.1\end{array}$ & $\begin{array}{l}17.33 \\
12.71 \\
1.29 \\
47.15\end{array}$ & $\begin{array}{l}44.31 \\
1.99 \\
40.97 \\
47.71\end{array}$ \\
\hline 75\% Oak & $\begin{array}{l}\text { Mean } \\
\text { Std. Dev. } \\
\text { Min } \\
\text { Max }\end{array}$ & $\begin{array}{l}861.44 \\
270.88 \\
351.31 \\
1347.50\end{array}$ & $\begin{array}{l}179.00 \\
56.29 \\
73.00 \\
280.00\end{array}$ & $\begin{array}{l}2989.57 \\
1000.64 \\
1205.23 \\
4715.27\end{array}$ & $\begin{array}{l}533338.82 \\
87184.07 \\
358403.42 \\
673415.68\end{array}$ & $\begin{array}{l}111.09 \\
31.0 \\
31.0 \\
266.1\end{array}$ & $\begin{array}{l}12.95 \\
15.89 \\
0.79 \\
60.3\end{array}$ & $\begin{array}{l}44.41 \\
2.360 \\
40.91 \\
50.25\end{array}$ \\
\hline $100 \%$ Oak & $\begin{array}{l}\text { Mean } \\
\text { Std. Dev. } \\
\text { Min } \\
\text { Max }\end{array}$ & $\begin{array}{l}852.61 \\
306.65 \\
380.19 \\
1684.38\end{array}$ & $\begin{array}{l}177.17 \\
63.72 \\
79.00 \\
350.00\end{array}$ & $\begin{array}{l}2896.20 \\
1031.48 \\
1267.38 \\
5479.30\end{array}$ & $\begin{array}{l}518725.31 \\
101634.89 \\
361062.85 \\
771090.20\end{array}$ & $\begin{array}{l}66.13 \\
21.52 \\
41.9 \\
112.6\end{array}$ & $\begin{array}{l}9.04 \\
10.18 \\
0.51 \\
44.68\end{array}$ & $\begin{array}{l}43.80 \\
1.966 \\
40.06 \\
49.15\end{array}$ \\
\hline
\end{tabular}




\section{Discussion}

\section{Furnish}

The weighted average length, shown in Table 1, for the first trial was 3.9 inches and weighted average width was 0.74 inches. The second trial revealed a weighted average length of 3.4 inches and weighted average width of 0.73 inches. These are comparable to the weighted average of the surface furnish produced by a mixed hardwood and softwood OSB facility. The mill's weighted average length after drying is 3.10 inches and the width is 0.56 inches

The oak results from the Pallmann trial appear to be comparable to slightly better than the mill's furnish. However, they may be affected by not drying the material in a rotary dryer like the mill does before measuring the weighted average length and width. Rotary drying tends to break up the furnish as it "tumbles" through the two - triple pass dryer drums. On the other hand, the oak strands were loaded by hand into bags, then boxes, and then air freighted from Germany. The handling of the oak strands may have created considerable strand breakage. The exact amount of breakage that occurred due to handling the material is unknown.

The fines content is excellent when compared to the mill's typical fines content. The mill normally has fines after the stranders, before drying, of around 15 to 25 percent with an average of about 19 percent, by weight. The oak fines content of 10.03 percent in the first trial and 4.5 percent in the second is superb in 
comparison. Fines content results are directly comparable since both were taken after stranding before screening and drying.

\section{Panels}

Evaluation of strength properties shows virtually no difference in control panels and panels containing $25 \%$ oak. This finding alone is of substantial importance because most mills exclude or limit the percentage of oak to less than $15 \%$ in their panels. By altering stranding variables such as knife grinding angle, knife pocket angle, cut time, strander rotational speed, etc. mills could utilize additional low grade oak.

Although statistical analysis showed significant differences beyond $25 \%$, many factors could have improved the performance of panels produced in this research. Some weak points in our production process include blending and forming. The lab blender worked well but resin was sprayed through nozzles designed for water. Industrial blenders contain atomizers made specifically for resin. Insufficient resin coverage caused poor bonding which resulted in reduced mechanical performance in all strength testing. Manual forming of the research mats also resulted in areas of low density which are evident in cross sectional views of some cut panels (figure 23.). Areas of low density reduce performance in all areas of strength testing. 


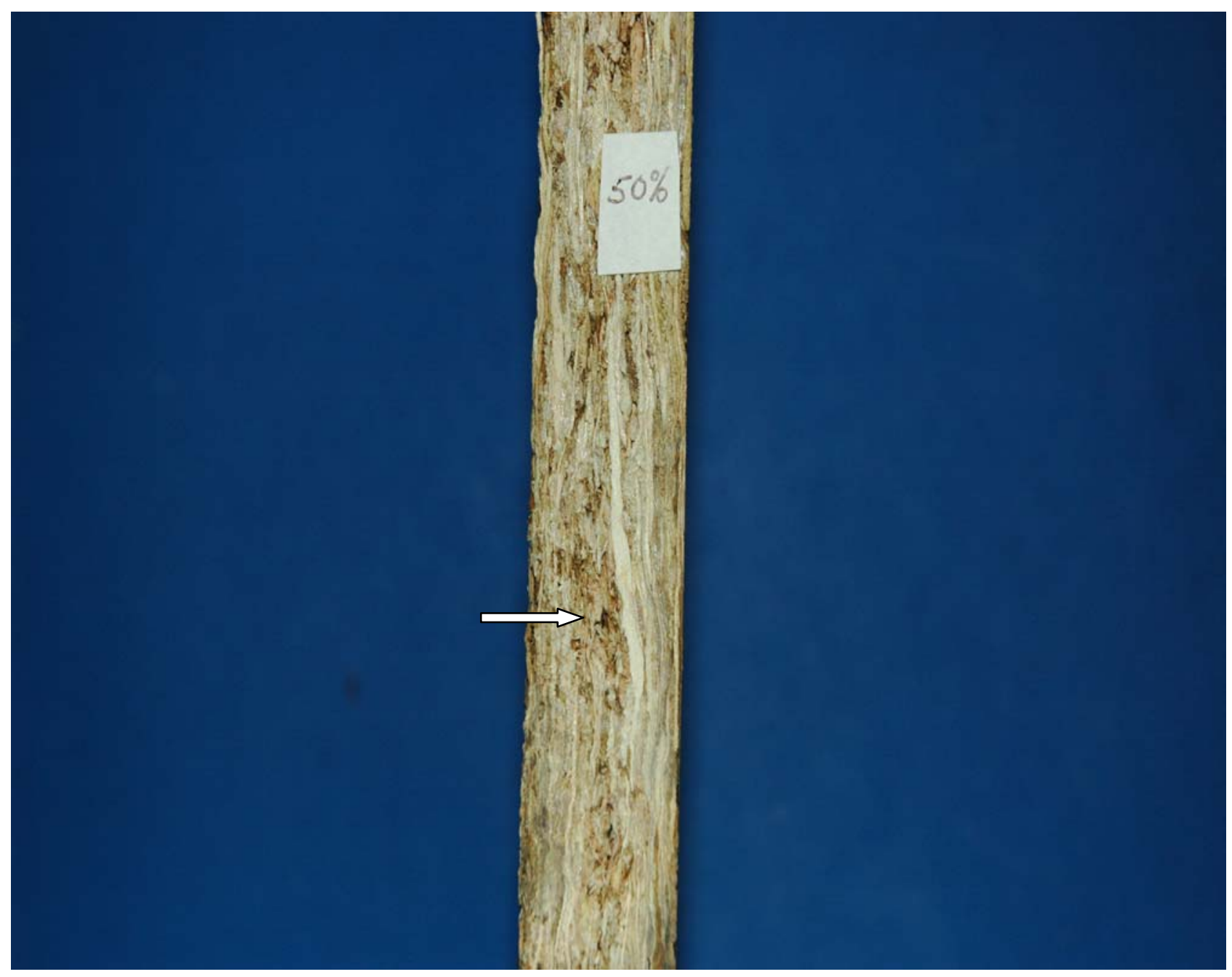

Figure 23. Area of low density

The decline in mechanical properties may be attributed to the reduction in the compaction ratio as the percentage of oak increased. Compaction ratio is the ratio of panel density to density of the wood species composing the panel. Higher density oak strands weigh more therefore it takes less of them to achieve the same overall panel density as shown in figure 24 . Having less strands in the panel reduces the surface to surface pressure that is required for optimal glue bonding. From these results it is obvious that in order to use even high quality oak strands in OSB production, the overall panel density will have to be 
increased. The amount of increase will be dependant on the percentage of oak that is used. Optimal compaction ratio is known to be approximately 1.3. Therefore, since the density of oak is approximately $46 \mathrm{lb} / \mathrm{ft}^{3}$, a $100 \%$ oak panel should slightly surpass that.

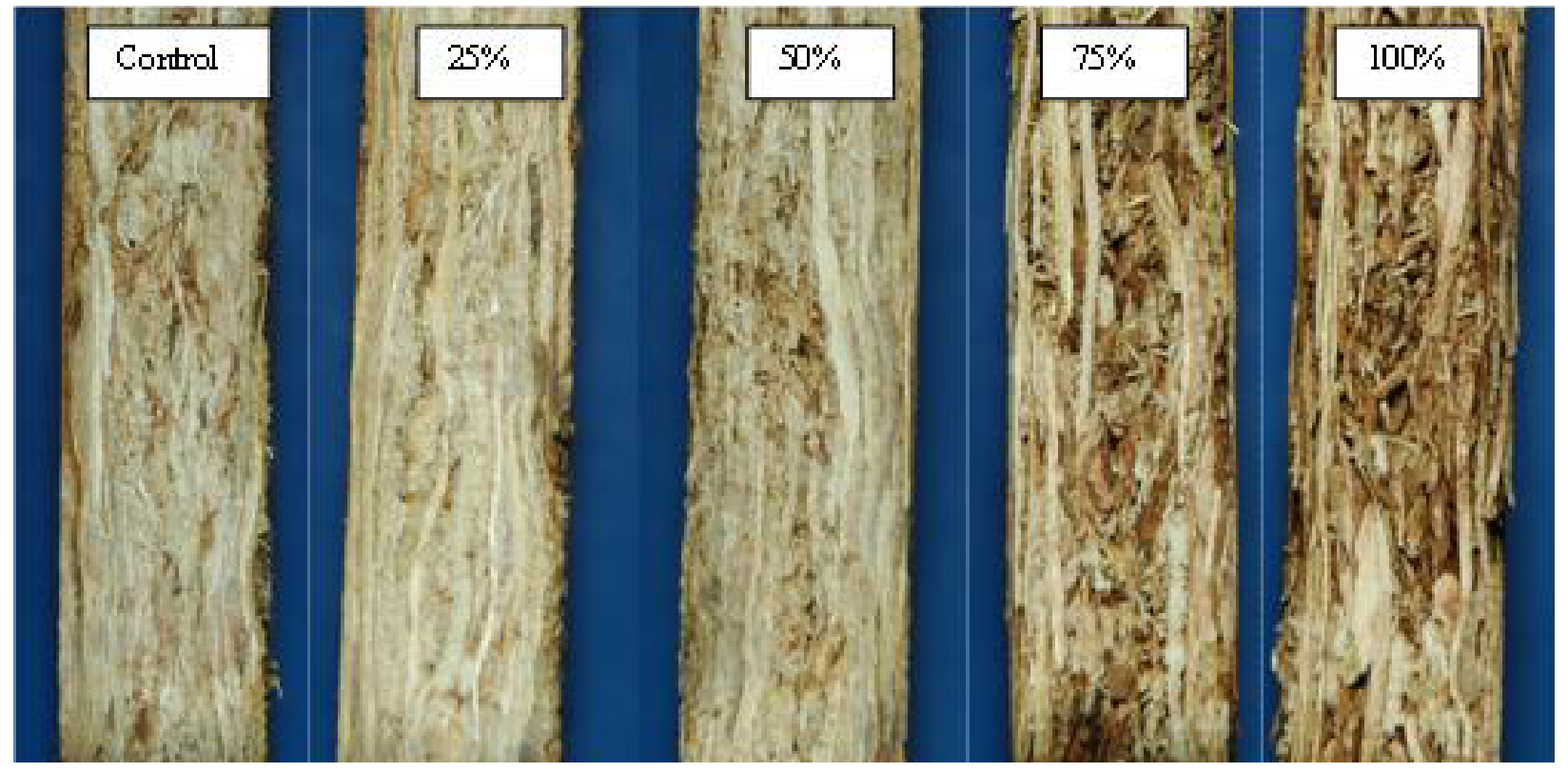

Figure 24. Reduced compaction with increase in oak percentage 


\section{Conclusions}

Strand quality, fines, and weighted average length and width are first-rate when compared to the mill's typical strand data. Results indicate that it is possible to produce a quality strand from oak by using an optimum combination of variables such as knife angle, cutting speed, and rotations per minute. In addition, it is possible to set up a strander to use oak without sacrificing machine life. Furthermore, it is possible to use oak species in quantities up to $25 \%$ by weight volume for OSB panel production. However, if usage in quantities over $25 \%$ is desired, overall panel density will have to be increased to keep the necessary compaction ratio closer to 1.3. Further research topics may include increasing density in panels containing oak to combat compaction ratio problems. Also, addition of a non-wood material to OSB panels could be one of many future research topics related to OSB. 


\section{List of References}

American Society for Testing and Materials. 1983. Standard test methods for evaluating properties of wood-based fiber and particle panel materials ASTM D 1037. ASTM, West Conshohocken, PA.

Angelini, M and Janssens D. (2004). OSB expanding beyond commodity sheathing applications. http://www.osbguide.com/pdf_news/SBA0407newsrelease.pdf

Avramidis, S. and Smith, L.(1989). The effect of resin content and face-to-core ratio on some properties of oriented strand board. Holzforschung, 43(2), 131133.

Building Online 2005. Structurwood Edge Gold Floor Panels Get 50-Year Warranty, 90 Day No Sand Guarantee.

http://www.buildingonline.com/news/viewnews.pl?id=4711

Davids, G., Dagher H., and Cassidy E. (2005). FRP-Reinforced Shear Walls and Diaphragms.

Elmendorf, A (1965). Oriented Strand Board. Patent 3, 164, 511.

Elmendorf, A (1965). Wood fibres from veneer waste. Proc.Forest Prod. Res. Soc. 3,53-57. 
Fisette, P. (2005). Choosing between Oriented Strand Board and Plywood.

http://www.umass.edu/bmatwt/publications/articles/osb vs plywood.html.

Grushecky S. et al. (2006). Inventory of Wood Residue in Southern West Virginia.

Maloney, T. (1977) Modern particleboard and dry-process fibreboard manufacturing. Miller Freeman Publications, Inc., California, USA.

Maloney, T. M. 1993. Modern Particleboard \& Dry-Process Fiberboard Manufacturing. Miller Freeman Inc. San Francisco, CA. 681 pp.

Partnership for Advancing Technology in Housing (2006). New Generation OSB Sub-flooring.

http://www.toolbase.org/techinv/techDetails.aspx?technologylD=260

TECO 2005. Resins Used in the Production of Oriented Strand Board.

http://www.tecotested.com

Weyerhaeuser OSB Mill. Heaters, WV 


\section{Appendix}

\section{SAS ANOVA output for MOE}

The SAS system 08:46 Friday, March 16, 200747

Dependent Variable: moe

$\begin{array}{lrrrrr}\text { Source } & \text { DF } & \begin{array}{r}\text { Sum of } \\ \text { Squares }\end{array} & \text { Mean Square } & \text { F Value } & \mathrm{Pr}>\mathrm{F} \\ \text { Model } & 30 & 692147460618 & 23071582021 & 8.39 & <.0001 \\ \text { Error } & 89 & 244776838601 & 2750301557.3 & \\ \text { Corrected Total } & 119 & 936924299219 & \end{array}$

$\begin{array}{llll}\text { R-Square } & \text { Coeff Var } & \text { Root MSE } & \text { moe Mean } \\ 0.738744 & 9.535364 & 52443.32 & 549987.6\end{array}$

$\begin{array}{lrrrrr}\text { Source } & \text { DF } & \text { Type I SS } & \text { Mean Square } & \text { F value } & \text { Pr }>F \\ \text { trt } & 4 & 57784755379 & 14446188845 & 5.25 & 0.0008 \\ \text { panel2(trt) } & 25 & 360509991376 & 14420399655 & 5.24 & <.0001 \\ \text { dens } & 1 & 273852713864 & 273852713864 & 99.57 & <.0001 \\ & & & & & \\ & & & & & \\ \text { Source } & \text { DF } & \text { Type III SS } & \text { Mean Square } & \text { F Value } & \text { Pr F } \\ & & & & & \\ \text { trt } & 4 & 65068979944 & 16267244986 & 5.91 & 0.0003 \\ \text { panel2(trt) } & 25 & 258001987697 & 10320079508 & 3.75 & <.0001 \\ \text { dens } & 1 & 273852713864 & 273852713864 & 99.57 & <.0001\end{array}$




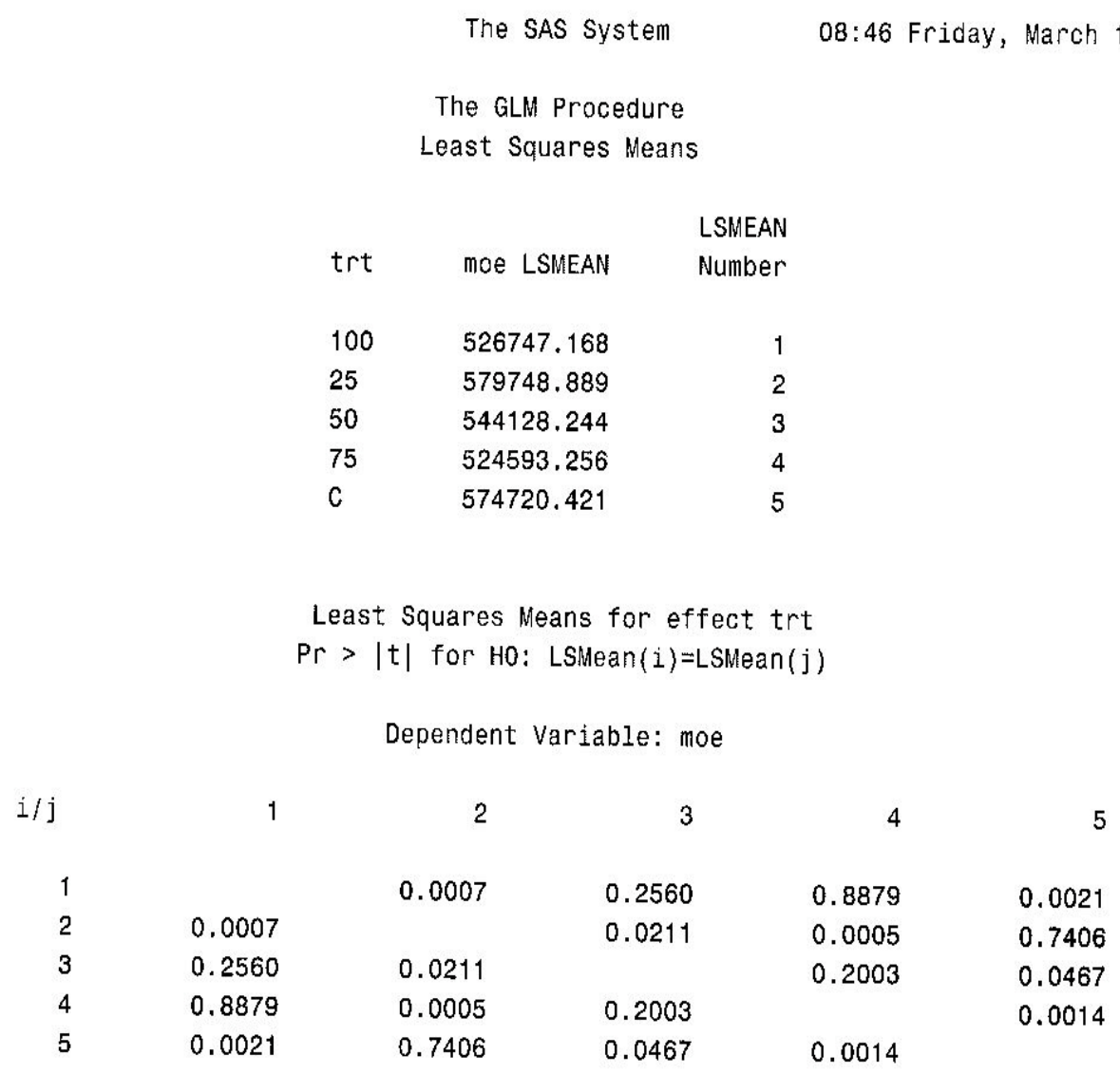

NOTE: To ensure overall protection level, only probabilities associated with pre-planned comparisons should be used. 


\section{SAS ANOVA output for Fmax}

The SAS System

08:46 Friday, March 16, 200744

The GLM Procedure

Dependent Variable: fmax

Source
Model
Error
Corrected Total

(2)

DF

\section{0}

89

119

Sum of
Squares
347239.0494
105804.9422
453043.9917

\section{R-Square \\ 0.766458}

Coeff Var

Root MSE

fmax Mean

16.20583

34.47926

212.7583

$\begin{array}{rrrrr}\text { DF } & \text { Type I SS } & \text { Mean Square } & \text { F Value } & \text { Pr }>\text { F } \\ & & & & \\ 4 & 104527.7833 & 26131.9458 & 21.98 & <.0001 \\ 25 & 139333.4583 & 5573.3383 & 4.69 & <.0001 \\ 1 & 103377.8078 & 103377.8078 & 86.96 & <.0001 \\ & & & & \\ \text { DF } & \text { Type III SS } & \text { Mean Square } & \text { F Value } & \text { Pr }>\text { F } \\ & & & & \\ 4 & 110648.7479 & 27662.1870 & 23.27 & <.0001 \\ 25 & 113632.9215 & 4545.3169 & 3.82 & <.0001 \\ 1 & 103377.8078 & 103377.8078 & 86.96 & <.0001\end{array}$




$\begin{array}{lrr}\text { The GLM Procedure } \\ \text { Least Squares Means } \\ \text { trt } & \text { fmax LSMEAN } & \begin{array}{r}\text { LSMEAN } \\ \text { Number }\end{array} \\ & & \\ 100 & 182.095342 & 1 \\ 25 & 238.936018 & 2 \\ 50 & 218.616359 & 3 \\ 75 & 173.626677 & 4 \\ \text { C } & 250.517271 & 5\end{array}$

Least Squares Means for effect trt $\operatorname{Pr}>|\mathrm{t}|$ for HO: LSMean $(i)=\operatorname{LSMean}(j)$

Dependent Variable: fmax

$\begin{array}{rrrrrr}i / j & 1 & 2 & 3 & 4 & 5 \\ 1 & & & & & <.0001 \\ 2 & <.0001 & <.0001 & 0.0004 & 0.4000 & 0.2477 \\ 3 & 0.0004 & 0.0446 & 0.0446 & <.0001 & 0.0019 \\ 4 & 0.4000 & <.0001 & <.0001 & <.0001 & <.0001 \\ 5 & <.0001 & 0.2477 & 0.0019 & <.0001 & \end{array}$

NOTE: To ensure overall protection level, only probabilities associated with pre-planned comparisons should be used. 


\section{SAS ANOVA output for MOR}

The SAS system

The GLM Procedure

Dependent Variable: mor

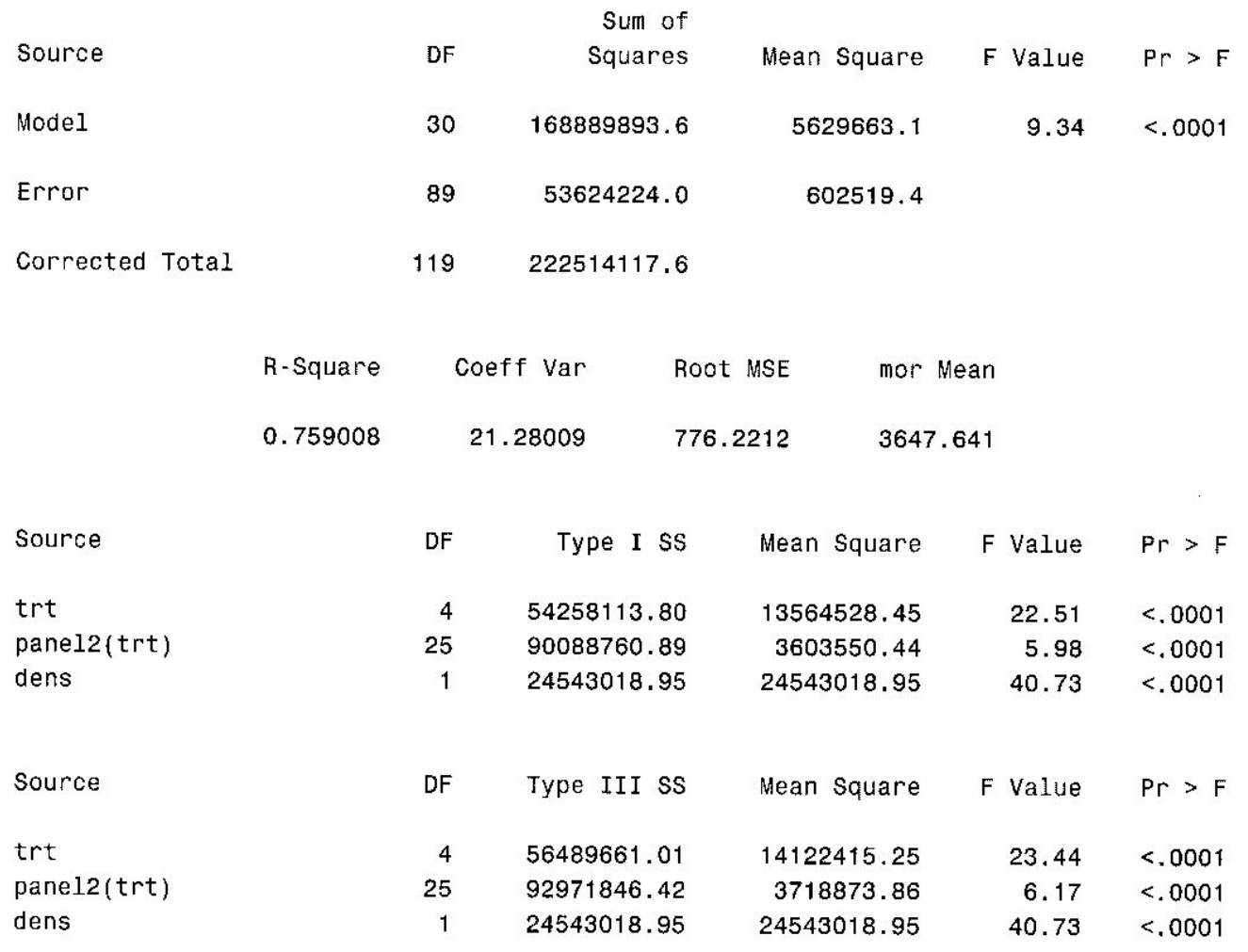


The GLM Procedure

Least Squares Means

$\begin{array}{llr}\text { trt } & \text { mor LSMEAN } & \begin{array}{l}\text { LSMEAN } \\ \text { Number }\end{array} \\ 100 & 2972.13807 & 1 \\ 25 & 3985.99339 & 2 \\ 50 & 3613.86812 & 3 \\ 75 & 2906.78172 & 4 \\ \text { C } & 4759.42156 & 5\end{array}$

Least Squares Means for effect trt $\mathrm{Pr}>|\mathrm{t}|$ for HO: LSMean( $i)=\operatorname{LSMean}(j)$

Dependent Variable: mor

$\begin{array}{rrrrrr}i / j & 1 & 2 & 3 & 4 & 5 \\ 1 & & <.0001 & 0.0054 & 0.7726 & <.0001 \\ 2 & <.0001 & & 0.1009 & <.0001 & 0.0009 \\ 3 & 0.0054 & 0.1009 & & 0.0022 & <.0001 \\ 4 & 0.7726 & <.0001 & 0.0022 & & <.0001 \\ 5 & <.0001 & 0.0009 & <.0001 & <.0001 & \end{array}$

NOTE: To ensure overall protection level, only probabilities associated with pre-planned comparisons should be used. 


\section{SAS ANOVA output for Mmax}

The GLM Procedure

Dependent Variable: $\operatorname{mmax}$

Source

Model

Error

Corrected Total

R-Square

0.758768

Source

trt

panel2(trt)

dens

Source

trt

panel2(trt)

dens
Sum of

DF

Squares

30

14986547.40

4764606.44

Mean Square

$F$ Value $\quad \mathrm{Pr}>\mathrm{F}$

89

119

19751153.83
499551.58

$9.33<.0001$
53534.90

$\begin{array}{lll}\text { Coeff Var } & \text { Root MSE } & \text { mmax Mean } \\ 21.73719 & 231.3761 & 1064.425\end{array}$

DF

Type I SS

Mean Square

$\mathrm{F}$ Value $\mathrm{Pr}>\mathrm{F}$

4

4884081.355

1221020.339

$22.81<.0001$

8327447.438

333097.898

$6.22<.0001$

1

1775018.605

1775018.605

$33.16<.0001$

DF

Type III SS

Mean Square

F value

1269121.761

336679.915

1775018.605

$23.71<.0001$

$6.29<.0001$

$33.16<.0001$ 
The GLM Procedure

Least Squares Means

$\begin{array}{lrr}\text { trt } & \text { mmax LSMEAN } & \begin{array}{r}\text { LSMEAN } \\ \text { Number }\end{array} \\ 100 & 873.03772 & \\ 25 & 1148.44566 & 2 \\ 50 & 1054.54952 & 3 \\ 75 & 839.17229 & 4 \\ \mathrm{C} & 1406.91959 & 5\end{array}$

Least Squares Means for effect trt

$\mathrm{Pr}>|\mathrm{t}|$ for HO: LSMean $(\mathrm{i})=\operatorname{LSMean}(\mathrm{j})$

Dependent Variable: $\operatorname{mmax}$

$\begin{array}{rrrrrr}i / j & 1 & 2 & 3 & 4 & 5 \\ 1 & & <.0001 & 0.0082 & 0.6156 & <.0001 \\ 2 & <.0001 & & 0.1641 & <.0001 & 0.0002 \\ 3 & 0.0082 & 0.1641 & & 0.0018 & <.0001 \\ 4 & 0.6156 & <.0001 & 0.0018 & & <.0001 \\ 5 & <.0001 & 0.0002 & <.0001 & <.0001 & \end{array}$

NOTE: To ensure overall protection level, only probabilities associated with pre-planned comparisons should be used. 